\title{
An objective prior error quantification for regional atmospheric inverse applications
}

\author{
P. Kountouris ${ }^{1}$, C. Gerbig ${ }^{1}$, K.-U. Totsche ${ }^{2}$, A. J. Dolman ${ }^{3}$, A. G. C. A. Meesters ${ }^{3}$, G. Broquet ${ }^{4}$, F. Maignan ${ }^{4}$, B. Gioli ${ }^{5}$, \\ L. Montagnani ${ }^{6,7}$, and C. Helfter ${ }^{8}$ \\ ${ }^{1}$ Max Planck Institute for Biogeochemistry, Jena, Germany \\ ${ }^{2}$ Institute of Geosciences, Department of Hydrology, Friedrich-Schiller-Universität, Jena, Germany \\ ${ }^{3}$ VU University Amsterdam, Amsterdam, the Netherlands \\ ${ }^{4}$ Laboratoire des Sciences du Climat et de l'Environnement, CEA-CNRS-UVSQ, UMR8212, IPSL, Gif-sur-Yvette, France \\ ${ }^{5}$ Institute of Biometeorology, IBIMET CNR, Florence, Italy \\ ${ }^{6}$ Faculty of Science and Technology, Free University of Bolzano, Piazza Università 5, 39100 Bolzano, Italy \\ ${ }^{7}$ Forest Services, Autonomous Province of Bolzano, Via Brennero 6, 39100 Bolzano, Italy \\ ${ }^{8}$ Centre for Ecology and Hydrology, Edinburgh, UK
}

Correspondence to: P. Kountouris (pkount@bgc-jena.mpg.de)

Received: 5 May 2015 - Published in Biogeosciences Discuss.: 23 June 2015

Revised: 24 November 2015 - Accepted: 3 December 2015 - Published: 16 December 2015

\begin{abstract}
Assigning proper prior uncertainties for inverse modelling of $\mathrm{CO}_{2}$ is of high importance, both to regularise the otherwise ill-constrained inverse problem and to quantitatively characterise the magnitude and structure of the error between prior and "true" flux. We use surface fluxes derived from three biosphere models - VPRM, ORCHIDEE, and 5PM - and compare them against daily averaged fluxes from 53 eddy covariance sites across Europe for the year 2007 and against repeated aircraft flux measurements encompassing spatial transects. In addition we create synthetic observations using modelled fluxes instead of the observed ones to explore the potential to infer prior uncertainties from modelmodel residuals. To ensure the realism of the synthetic data analysis, a random measurement noise was added to the modelled tower fluxes which were used as reference. The temporal autocorrelation time for tower model-data residuals was found to be around 30 days for both VPRM and ORCHIDEE but significantly different for the 5PM model with 70 days. This difference is caused by a few sites with large biases between the data and the 5PM model. The spatial correlation of the model-data residuals for all models was found to be very short, up to few tens of kilometres but with uncertainties up to $100 \%$ of this estimation. Propagating this error structure to annual continental scale yields an uncertainty of $0.06 \mathrm{Gt} \mathrm{C}$ and strongly underestimates uncertainties typically
\end{abstract}

used from atmospheric inversion systems, revealing another potential source of errors. Long spatial e-folding correlation lengths up to several hundreds of kilometres were determined when synthetic data were used. Results from repeated aircraft transects in south-western France are consistent with those obtained from the tower sites in terms of spatial autocorrelation (35 km on average) while temporal autocorrelation is markedly lower (13 days). Our findings suggest that the different prior models have a common temporal error structure. Separating the analysis of the statistics for the model data residuals by seasons did not result in any significant differences of the spatial e-folding correlation lengths.

\section{Introduction}

Atmospheric inversions are widely used to infer surface $\mathrm{CO}_{2}$ fluxes from observed $\mathrm{CO}_{2}$ dry mole fractions with a Bayesian approach (Ciais et al., 2000; Gurney et al., 2002; Lauvaux et al., 2008). In this approach a limited number of observations of atmospheric $\mathrm{CO}_{2}$ mixing ratios are used to solve for generally a much larger number of unknowns, making this an ill-posed problem. By using prior knowledge of the surface-atmosphere exchange fluxes and an associated prior uncertainty, the information retrieved in the inversion from 
the observations is spread out in space and time corresponding to the spatiotemporal structure of the prior uncertainty. In this way, the solution of the otherwise ill-posed problem is regularised in the sense that the optimisation problem becomes one with a unique solution. This prior knowledge typically comes from process-oriented or diagnostic biosphere models that simulate the spatiotemporal patterns of terrestrial fluxes, as well as from inventories providing information regarding anthropogenic fluxes such as energy consumption, transportation, industry, and forest fires.

The Bayesian formulation of the inverse problem is a balance between the a priori and the observational constraints. It is crucial to introduce a suitable prior flux field and assign to it proper uncertainties. When prior information is combined with inappropriate prior uncertainties, this can lead to poorly retrieved fluxes (Wu et al., 2011). Here, we are interested in biosphere-atmosphere exchange fluxes and their uncertainties, and we make the usual assumption that the uncertainties in anthropogenic emission fluxes are not strongly affecting the atmospheric observations at the rural sites that are used in the regional inversions of biosphere-atmosphere fluxes.

Typically inversions assume that prior uncertainties have a normal and unbiased distribution and thus can be represented in the form of a covariance matrix. The covariance matrix is a method to weigh our confidence of the prior estimates. The prior error covariance determines to what extent the posterior flux estimates will be constrained by the prior fluxes. Ideally the prior uncertainty should reflect the mismatch between the prior guess and the actual (true) biosphere-atmosphere exchange fluxes. In this sense it needs to also have the corresponding error structure with its spatial and temporal correlations.

A number of different assumptions of the error structure have been considered by atmospheric $\mathrm{CO}_{2}$ inversion studies. Coarser-scale inversions often neglect spatial and temporal correlations as the resolution is low enough for the inverse problem to be regularised (Bousquet et al., 1999; Rödenbeck et al., 2003a) or assume large spatial correlation lengths (several hundreds of kilometres) over land (Houweling et al., 2004; Rödenbeck et al., 2003b). For the former case, large correlation scales are implicitly assumed since fluxes within a grid cell are fully correlated. For regional-scale inversions, with higher spatial grid resolutions which are often less than $100 \mathrm{~km}$, the spatial correlations are decreased (Chevallier et al., 2012) and the error structure need to be carefully defined. A variety of different assumptions exist. This is because only recently an objective approach to define prior uncertainties based on mismatch between modelled and observed fluxes has been developed (Chevallier et al., 2006, 2012). In some regional studies, the same correlations are used as in largescale inversions in order to regularise the problem, although the change of resolution could lead to different correlation scales (Schuh et al., 2010). Alternatively, they are defined with a correlation length representing typical synoptic meteorological systems (Carouge et al., 2010). In other cases, ad hoc solutions are adopted, where the correlation lengths are assumed to be smaller than in the case of global inversions (Peylin et al., 2005), or derived from climatological and ecological considerations (Peters et al., 2007), where correlation lengths only within the same ecosystem types have a value of $2000 \mathrm{~km}$. In addition some studies use a number of different correlation structures in order to analyse which seems to be the most appropriate one based on cross-validation of the simulated against observed $\mathrm{CO}_{2}$ mole fractions. The simulated mole fractions were derived using the influence functions and the inverted fluxes (Lauvaux et al., 2012). Michalak et al. (2004) applied a geostatistical approach based on the Bayesian method, in which the prior probability density function is based on an assumed form of the spatial and temporal correlation and no prior flux estimates are required. It optimises the prior error covariance parameters, the variance, and the spatial correlation length by maximising the probability density function of the observations with respect to these parameters.

A recent study by Broquet et al. (2013) obtained good agreements between the statistical uncertainties as derived from the inversion system and the actual misfits calculated by comparing the posterior fluxes to local flux measurements at the European and 1-month scales. These good agreements relied largely on their definition of the prior uncertainties based on the statistics derived in an objective way from model-data mismatch by Chevallier et al. (2006, 2012). In these studies, modelled daily fluxes from a site-scale configuration of the ORCHIDEE model are compared with flux observations made within the global FLUXNET site network, based on the eddy covariance method (Baldocchi et al., 2001), and a statistical upscaling technique is used to derive estimates of the uncertainties in ORCHIDEE simulations at lower resolutions. While typical inversion systems have a resolution ranging from tens of kilometres up to several degrees (hundreds of kilometres), with the true resolution of the inverse flux estimates being even coarser, the spatial representativity of the flux observations typically covers an area with a radius of around $1 \mathrm{~km}$. Considering also the scarcity of the observing sites in the flux network, the spatial information they bring is limited without methods for up-scaling such as the one applied by Chevallier et al. (2012). Typical approaches to up-scale site level fluxes deploy for example model tree algorithms, a machine learning algorithm which is trained to predict carbon flux estimates based on meteorological data, vegetation properties and types (Jung et al., 2009; Xiao et al., 2008), or neural networks (Papale and Valentini, 2003). Nevertheless eddy covariance measurements provide a unique opportunity to infer estimates of the prior uncertainties by examining model-data misfits for spatial and temporal autocorrelation structures.

Hilton et al. (2012) studied also the spatial modeldata residual error structure using a geostatistical method. Hilton's study is focused on the seasonal scale, i.e. investigated residual errors of seasonally aggregated fluxes. How- 
ever, the state space (variables to be optimized considering also their temporal resolution) of current inversion systems is often at high temporal resolution (daily or even 3-hourly optimisations). Further, the statistical consistency between the error covariance and the state space is crucial. Thus the error structure at the daily timescale is of interest here and can be used in atmospheric inversions of the same temporal resolution. Similar to Hilton's study we select an exponentially decaying model to fit the spatial residual autocorrelation.

In this study, we augment the approach of Chevallier et al. $(2006,2012)$ to a multi-model-data comparison, investigating among others a potential generalisation of the error statistics, suitable to be applied by inversions using different biosphere models as priors. This expectation is derived from the observation that the biosphere models, despite their potential differences, typically have much information in common, such as driving meteorological fields, land use maps, or remotely sensed vegetation properties, and sometimes even process descriptions. We evaluate model-model mismatches to (I) investigate intra-model autocorrelation patterns and (II) to explore whether they are consistent with the spatial and temporal e-folding correlation lengths of the model-data mismatch comparisons. Model comparisons have been used in the past to infer the structure of the prior uncertainties. For example, Rödenbeck et al. (2003b) used prior correlation lengths based on statistical analyses of the variations within an ensemble of biospheric models. This approach is to a certain degree questionable, as it is unclear how far the ensemble of models actually can be used as representative of differences between modelled and true fluxes. However, if a relationship between model-data and model-model statistics can be established for a region with a dense network of flux observations, it could also be used to derive prior error structure for regions with a less dense observational network.

Moreover, to improve the knowledge of spatial flux error patterns, we make use of a unique set of aircraft fluxes measured on $2 \mathrm{~km}$ spatial windows along intensively sampled transects of several tens of kilometres, ideally resolving spatial and temporal variability of ecosystem fluxes across the landscape without the limitation of the flux network with spatial gaps in between measurement locations. Lauvaux et al. (2009) compared results of a regional inversion against measurements of fluxes from aircraft and towers, while this is the first attempt to use aircraft flux measurements to assess spatial and temporal error correlation structures.

This study focuses on the European domain for 2007 (tower data) and 2005 (aircraft data) and uses output from high-resolution biosphere models that have been used for regional inversions. Eddy covariance tower fluxes were derived from the FLUXNET ecosystem network (Baldocchi et al., 2001), while aircraft fluxes were acquired within the CarboEurope Regional Experiment (CERES) in southern France. The methods and basic information regarding the models are summaries in Sect. 2. The results from model- data and model-model comparisons are detailed in Sect. 3. Discussion and conclusions are following in Sect. 4.

\section{Data and methods}

Appropriate error statistics for the prior error covariance matrix are derived from comparing the output of three biosphere models which are used as priors for regional-scale inversions with flux data from the ecosystem network and aircraft. We investigate spatial and temporal autocorrelation structures of the model-data residuals. The temporal autocorrelation is a measure of similarity between residuals at different times but at the same location as a function of the time difference. The spatial autocorrelation refers to the correlation, at a given time, of the model-data residuals at different locations as a function of spatial distance. With this analysis we can formulate and fit an error model such as an exponentially decaying model, which can be directly used in the mesoscale inversion system to describe the prior error covariance.

\subsection{Observations}

A number of tower sites within the European domain, roughly expanding from -12 to $35^{\circ} \mathrm{E}$ and 35 to $61^{\circ} \mathrm{N}$ (see also Fig. 1), provide us with direct measurements of $\mathrm{CO}_{2}$ biospheric fluxes using the eddy covariance technique. This technique computes fluxes from the covariance between vertical wind velocity and $\mathrm{CO}_{2}$ dry mole fraction (Aubinet et al., 2000). We use Level 3 quality-checked half-hourly observations of net ecosystem exchange fluxes (NEE), downloaded from the European Flux Database (www.europe-fluxdata.eu) and listed by site in Table 1. Each site is categorised into different vegetation types (Table 1). A land cover classification is used to label the sites as crop (17 sites), deciduous forest (4), evergreen forest (17), grassland (8), mixed forest (3), savannah (1 site), and shrub land (1). For the current study we focus on observations from these 53 European sites during the year 2007 (Fig. 1).

Additionally, aircraft fluxes are used, obtained with an eddy covariance system installed onboard a SkyArrow ERA aircraft (Gioli et al., 2006). Flights were made in southern France during CERES (CarboEurope Regional Experiment) from 17 May to 22 June 2005. Eddy covariance fluxes were computed on $2 \mathrm{~km}$ length spatial windows along transects of $69 \mathrm{~km}$ above forest and $78 \mathrm{~km}$ above agricultural land, flown 52 and 54 times respectively, covering the daily course. Exact routes are reported in Dolman et al. (2006).

\subsection{Biosphere models}

We simulate $\mathrm{CO}_{2}$ terrestrial fluxes for 2007 with three different biosphere models described in the following. The Vegetation Photosynthesis and Respiration Model (VPRM) (Mahadevan et al., 2008), used to produce prior flux fields for inverse studies (Pillai et al., 2012), is a diagnostic model that 
Table 1. Eddy covariance sites measuring $\mathrm{CO}_{2}$ fluxes that were used in the analysis. The land cover classification used is coded as follows: CRO, DCF, EVG, MF, GRA, OSH, and SAV for crops, deciduous forest, evergreen forest, mixed forest, grass, shrub, and savanna respectively.

\begin{tabular}{|c|c|c|c|c|c|}
\hline Site code & Site name & $\begin{array}{l}\text { Land cover } \\
\text { classification }\end{array}$ & Latitude & Longitude & Citation \\
\hline BE-Bra & Brasschaat & MF & 51.31 & 4.52 & Gielen et al. (2013) \\
\hline BE-Lon & Lonzée & $\mathrm{CRO}$ & 50.55 & 4.74 & Moureaux et al. (2006) \\
\hline BE-Vie & Vielsalm & MF & 50.31 & 6.00 & Aubinet et al. (2001) \\
\hline $\mathrm{CH}-\mathrm{Cha}$ & Chamau & GRA & 47.21 & 8.41 & Zeeman et al. (2010) \\
\hline CH-Dav & Davos & ENF & 46.82 & 9.86 & Zweifel et al. (2010) \\
\hline CH-Fru & Frebel & GRA & 47.12 & 8.54 & Zeeman et al. (2010) \\
\hline $\mathrm{CH}-\mathrm{Lae}$ & Lägern & MF & 47.48 & 8.37 & Etzold et al. (2010) \\
\hline $\mathrm{CH}-\mathrm{Oe} 1$ & $\begin{array}{l}\text { Oensingen } \\
\text { grassland }\end{array}$ & GRA & 47.29 & 7.73 & Ammann et al. (2009) \\
\hline $\mathrm{CH}-\mathrm{Oe} 2$ & Oensingen crop & $\mathrm{CRO}$ & 47.29 & 7.73 & Dietiker et al. (2010) \\
\hline CZ-BK1 & Bily Kriz forest & ENF & 49.50 & 18.54 & Taufarova et al. (2014) \\
\hline DE-Geb & Gebesee & $\mathrm{CRO}$ & 51.10 & 10.91 & Kutsch et al. (2010) \\
\hline DE-Gri & Grillenburg & GRA & 50.95 & 13.51 & Prescher et al. (2010) \\
\hline DE-Hai & Hainich & DBF & 50.79 & 10.45 & Knohl et al. (2003) \\
\hline DE-Kli & Klingenberg & $\mathrm{CRO}$ & 50.89 & 13.52 & Prescher et al. (2010) \\
\hline DE-Tha & Tharandt & $\mathrm{ENF}$ & 50.96 & 13.57 & Prescher et al. (2010) \\
\hline DK-Lva & Rimi & GRA & 55.68 & 12.08 & Soussana et al. (2007) \\
\hline ES-Agu & Aguamarga & $\mathrm{OSH}$ & 36.94 & -2.03 & Rey et al. (2012) \\
\hline ES-ES2 & $\begin{array}{l}\text { El Saler-Sueca } \\
\text { (Valencia) }\end{array}$ & CRO & 39.28 & -0.32 & - \\
\hline ES-LMa & $\begin{array}{l}\text { Las Majadas de } \\
\text { Tietar (Caceres) }\end{array}$ & SAV & 39.94 & -5.77 & Casals et al. (2011) \\
\hline FI-Hyy & Hyytiälä & ENF & 61.85 & 24.30 & Suni et al. (2003) \\
\hline FR-Aur & Aurade ̌̌ & $\mathrm{CRO}$ & 43.55 & 1.11 & Tallec et al. (2013) \\
\hline FR-Avi & Avignon & CRO & 43.92 & 4.88 & Garrigues et al. (2014) \\
\hline FR-Fon & Fontainebleau & DBF & 48.48 & 2.78 & Delpierre et al. (2009) \\
\hline FR-Hes & Hesse & $\mathrm{DBF}$ & 48.67 & 7.07 & Longdoz et al. (2008) \\
\hline FR-LBr & Le Bray & ENF & 44.72 & -0.77 & Jarosz el al. (2008) \\
\hline FR-Lq1 & $\begin{array}{l}\text { Laqueuille } \\
\text { intensive }\end{array}$ & GRA & 45.64 & 2.74 & Klumpp et al. (2011) \\
\hline FR-Lq2 & $\begin{array}{l}\text { Laqueuille } \\
\text { extensive }\end{array}$ & GRA & 45.64 & 2.74 & Klumpp et al. (2011) \\
\hline FR-Mau & Mauzac & GRA & 43.39 & 1.29 & Albergel et al. (2010) \\
\hline FR-Pue & Puéchabon & $\mathrm{EBF}$ & 43.74 & 3.60 & Allard et al. (2008) \\
\hline HU-Mat & Matra & CRO & 47.85 & 19.73 & Nagy et al. (2007) \\
\hline IT-Amp & Amplero & GRA & 41.90 & 13.61 & Barcza et al. (2007) \\
\hline IT-BCi & Borgo Cioffi & $\mathrm{CRO}$ & 40.52 & 14.96 & Kutsch et al. (2010) \\
\hline IT-Cas & Castellaro & $\mathrm{CRO}$ & 45.07 & 8.72 & Meijide et al. (2011) \\
\hline IT-Col & Collelongo & $\mathrm{DBF}$ & 41.85 & 13.59 & Guidolotti et al. (2013) \\
\hline IT-Cpz & Castelporziano & $\mathrm{EBF}$ & 41.71 & 12.38 & Garbulsky et al. (2008) \\
\hline IT-Lav & Lavarone & ENF & 45.96 & 11.28 & Marcolla et al. (2003) \\
\hline IT-Lec & Lecceto & $\mathrm{EBF}$ & 43.30 & 11.27 & Chiesi et al. (2011) \\
\hline IT-LMa & Malga Arpaco & GRA & 46.11 & 11.70 & Soussana et al. (2007) \\
\hline IT-MBo & Monte Bondone & GRA & 46.01 & 11.05 & Marcolla et al. (2011) \\
\hline IT-Ren & Renon & ENF & 46.59 & 11.43 & Marcolla et al. (2005) \\
\hline IT-Ro2 & Roccarespampani 2 & DBF & 42.39 & 11.92 & Wei et al. (2014) \\
\hline IT-SRo & San Rossore & $\mathrm{ENF}$ & 43.73 & 10.28 & Matteucci et al. (2014) \\
\hline NL-Dij & Dijkgraaf & $\mathrm{CRO}$ & 51.99 & 5.65 & Jans et al. (2010) \\
\hline NL-Loo & Loobos & ENF & 52.17 & 5.74 & Elbers et al. (2011) \\
\hline NL-Lut & Lutjewad & $\mathrm{CRO}$ & 53.40 & 6.36 & Moors et al. (2010) \\
\hline PT-Esp & Espirra & $\mathrm{EBF}$ & 38.64 & -8.60 & Gabriel et al. (2013) \\
\hline PT-Mi2 & Mitra IV (Tojal) & GRA & 38.48 & -8.02 & Jongen et al. (2011) \\
\hline SE-Kno & Knottœsen & ENF & 61.00 & 16.22 & 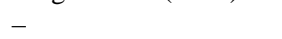 \\
\hline SE-Nor & Norunda & ENF & 60.09 & 17.48 & - \\
\hline SE-Sk1 & Skyttorp 1 & ENF & 60.13 & 17.92 & - \\
\hline SK-Tat & Tatra & ENF & 49.12 & 20.16 & - \\
\hline UK-AMo & Auchencorth Moss & GRA & 55.79 & -3.24 & Helfter et al. (2015) \\
\hline UK-EBu & Easter Bush & GRA & 55.87 & -3.21 & Skiba et al. (2013) \\
\hline
\end{tabular}




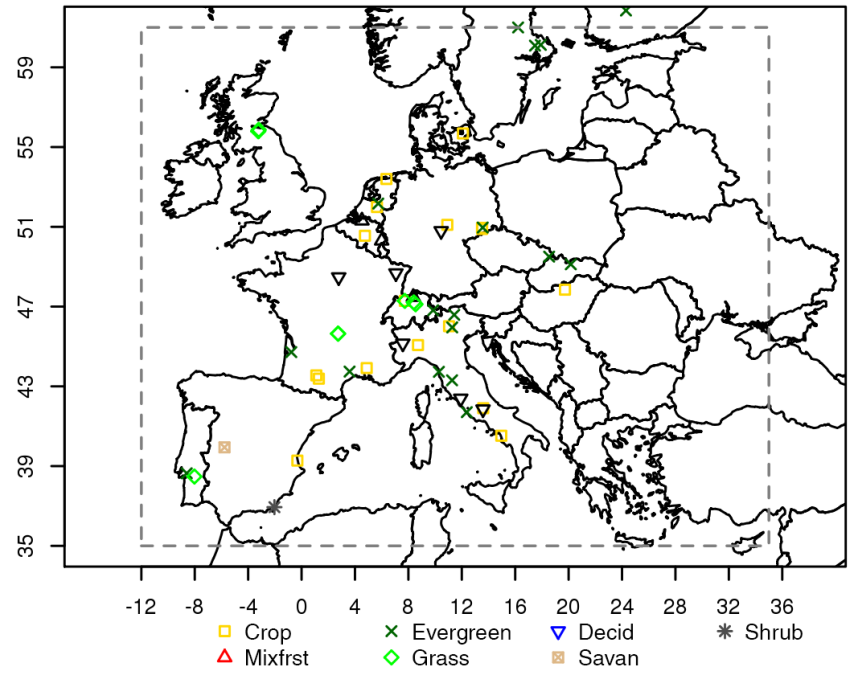

Figure 1. Eddy covariance sites used in the study. The dashed line delimits the exact domain used to calculate the aggregated fluxes.

uses the enhanced vegetation index (EVI) and land surface water index (LSWI) from MODIS, a vegetation map (Synmap, Jung et al., 2006) and meteorological data (temperature at $2 \mathrm{~m}$ and downward shortwave radiative flux extracted from ECMWF short-term forecast fields at $0.25^{\circ}$ resolution) to derive gross biogenic fluxes. VPRM parameters controlling respiration and photosynthesis for different vegetation types (a total of four parameters per vegetation type) were optimized using eddy covariance data for the year 2005 collected during the CarboEuropeIP project (Pillai et al., 2012). For this study, VPRM fluxes are provided at hourly temporal resolution and at three spatial resolutions of 1,10 and $50 \mathrm{~km}$ (referred to as VPRM1, VPRM10, and VPRM50). The difference between the 1,10 , and $50 \mathrm{~km}$ resolution version is the aggregation of MODIS indices to either 1,10 , or $50 \mathrm{~km}$; otherwise the same meteorology and VPRM parameters are used. At $10 \mathrm{~km}$ resolution VPRM uses a tiled approach, with fractional coverage for the different vegetation types and vegetation-typespecific values for MODIS indices. For the comparison with the aircraft data VPRM produced fluxes for 2005 at $10 \mathrm{~km}$ spatial resolution.

The Organising Carbon and Hydrology In Dynamic Ecosystems (ORCHIDEE) model (Krinner et al., 2005) is a process-based site scale to global land surface model that simulates the water and carbon cycle using meteorological forcing (temperature, precipitation, humidity, wind, radiation, pressure). The water balance is solved at a half-hourly time step while the main carbon processes (computation of a prognostic leaf area index (LAI), allocation, respiration, turnover) are called on a daily basis. It uses a tiled approach, with fractional coverage for 13 plant functional types (PFTs). It has been extensively used as prior information in regionaland global-scale inversions (Piao et al., 2009; Broquet et al., 2013). For the present simulation, we use a global configura- tion of the version 1.9.6 of ORCHIDEE, where no parameter has been optimized against eddy covariance data. The model is forced with $0.5^{\circ}$ WFDEI meteorological fields (Weedon et al., 2014). The PFT map is derived from an Olson land cover map (Olson, 1994) based on AVHRR remote sensing data (Eidenshink and Faundeen, 1994). The fluxes are diagnosed at 3-hourly temporal resolution and at $0.5^{\circ}$ horizontal resolution.

The "5 parameter model" (5PM) (Groenendijk et al., 2011), also used in atmospheric inversions (Tolk et al., 2011; Meesters et al., 2012), is a physiological model describing transpiration, photosynthesis, and respiration. It uses MODIS LAI at $10 \mathrm{~km}$ resolution, meteorological data (temperature, moisture, and downward shortwave radiative flux, presently from ECMWF at $0.25^{\circ}$ resolution), and differentiates PFTs for different vegetation types and climate regions. 5PM fluxes are at hourly temporal resolution. The optimisation has been done with eddy covariance (EC) data from FLUXNET as described (except for heterotrophic respiration) in Groenendijk et al. (2011). Regarding the heterotrophic respiration, an ad hoc optimisation using FLUXNET EC data from 2007 was performed since no previous optimisation was available.

Modelled fluxes for all above mentioned sites have been provided by the different models by extracting the fluxes from the grid cells which encompass the EC station location using vegetation-type-specific simulated fluxes, i.e. using the vegetation type within the respective grid cell for which the eddy covariance site is assumed representative. For most of the sites the same vegetation type was used for model extraction as long as this vegetation type is represented within the grid cell. As VPRM uses a tile approach, for two cases (IT-Amp and IT-MBo) the represented vegetation type (crop) differs from the actual one (grass). For these cases, the fluxes corresponding to crop were extracted. Fluxes were aggregated to daily fluxes in the following way: first, fluxes from VPRM and 5PM as well as the observed fluxes were temporally aggregated to match with the ORCHIDEE 3-hourly resolution; in a second step we created gaps in the modelled fluxes where no observations were available; the last step aggregated to daily resolution on the premise that (a) the gaps covered less than $50 \%$ of the day and (b) the number of gaps (number of individual 3-hourly missing values) during day and during night were similar (not different by more than a factor two) to avoid biasing.

Spatial and temporal correlation structures and the standard deviation of flux residuals (model-observations) were examined for daily fluxes over the year 2007. Simulated fluxes from the different models are at different spatial resolution, which makes comparisons difficult to interpret. For the model-data residual analysis, the models VPRM1, VPRM10, ORCHIDEE, and 5PM were used. We note that VPRM1 with $1 \mathrm{~km}$ resolution is considered compatible when comparing with local measurements. For the model-model analysis we use VPRM50 at $50 \mathrm{~km}$ resolution when comparing with ORCHIDEE fluxes as both models share the 
same resolution. VPRM10 is considered also appropriate for comparisons with 5PM model as they both share the same resolution (MODIS radiation resolution of $1 \mathrm{~km}$ aggregated to $10 \mathrm{~km}$ and meteorological resolution at $0.25^{\circ}$ ). Further, we compare VPRM50 with 5PM to investigate whether the different spatial resolution influences the correlation scale as a measure of how trustworthy the derived scales from ORCHIDEE-5PM comparisons might be.

For the aircraft analysis, only the VPRM was used since it is the only model with spatial resolution $(10 \mathrm{~km})$ comparable with aircraft flux footprint and capable of resolving spatial variability in relatively short flight distances. Aircraft NEE data, natively at $2 \mathrm{~km}$ resolution along the track, have been aggregated into $10 \mathrm{~km}$ segments to maximise the overlap with the VPRM grid, obtaining six grid points in forest transects and eight in agricultural land transects. Footprint areas of aircraft fluxes were computed with the analytical model of Hsieh et al. (2000), yielding an average footprint width containing $90 \%$ of the flux of $3.9 \mathrm{~km}$. Averaging also over the different wind directions (perpendicular or parallel to the flight direction) and taking into account the $10 \mathrm{~km}$ length of the segments, the area that the aircraft flux data corresponds to, is around $23.5 \mathrm{~km} \pm 12 \mathrm{~km}^{2}$. VPRM fluxes at each aircraft grid cell were extracted and then linearly interpolated to the time of each flux observation.

\subsection{Analysis of model-observation differences}

Observed and modelled fluxes are represented as the sum of the measured or simulated values and an error term respectively. When we compare modelled to observed data this error term is a combination of model (the prior uncertainty we are interested in) and observation error. Separating the observation error from the model error in the statistical analysis of the model-observation mismatch is not possible; therefore e-folding correlation length estimations do include the observation error term. Nevertheless, later in the analysis of model-model differences we assess the impact of the observation error on estimated e-folding correlation lengths.

The tower temporal autocorrelation is computed between the time series of model-observations differences $x_{l, i}$ at site $l$ and the same series lagged by a time unit $k$ (Eq. 1), where $\bar{x}$ is the overall mean and $\mathrm{N}$ the number of observations:

$r_{l}(k)=\frac{\sum_{i=1}^{N-k}\left(x_{l, i}-\overline{x_{l}}\right) \cdot\left(x_{l, i+k}-\overline{x_{l}}\right)}{\sum_{i=1}^{N}\left(x_{l, i}-\overline{x_{l}}\right)^{2}}$.

In order to reduce boundary effects in the computation of the autocorrelation at lag times around 1 year, the 1-year flux time series data (model and observations) for each site was replicated four times. This follows the approach of Chevallier et al. (2012), where sites with at least 3 consecutive years of measurements have been used.
In the current analysis we introduce the all-site temporal autocorrelation by simultaneously computing the autocorrelation for all the observation sites, where $M$ is the number of the sites:

$$
r(k)=\frac{\sum_{l=1}^{M} \sum_{i=1}^{N-k}\left(x_{l, i}-\overline{x_{l}}\right) \cdot\left(x_{l, i+k}-\overline{x_{l}}\right)}{\sum_{l=1}^{M} \sum_{i=1}^{N}\left(x_{l, i}-\overline{x_{l}}\right)^{2}} .
$$

Temporal correlation scales $\tau$ were derived by fitting an exponentially decaying model:

$r=(1-\alpha) \cdot e^{-\frac{t}{\tau}}$.

Here $t$ is the time lag. For the exponential fit, lags up to 180 days were used (thus the increase in correlations for lag times larger than 10 months is excluded). At 0 lag time the correlogram has a value of 1 (fully correlated); however for even small lag times this drops to values smaller than 1 , also known as the nugget effect. The nugget effect is driven by measurement errors and variations at distances (spatial or temporal) smaller than the sampling interval. For this we include the nugget effect variable $\alpha$.

The aircraft temporal autocorrelation was similarly computed according to Eq. (1) using VPRM, and the same exponentially decaying model (Eq. 3) was used to fit the individual flight flux data. The temporal interval was limited at 36 days by the experiment duration.

For the spatial analysis the correlation between modelobservation residuals at two different locations (i.e sites or aircraft grid points) separated by a specific distance was computed in a way similar to the temporal correlation and involved all possible pairs of sites and aircraft grid points. Additional data treatment for the spatial analysis was applied to reduce the impact of tower data gaps, as it is possible that the time series for two sites might have missing data at different times. Thus in order to have more robust results, we also examined spatial structures by setting a minimum threshold of 150 days of overlapping observations within each site pair. Furthermore spatial correlation was investigated for seasonal dependence, where seasons are defined as summer (JJA), autumn (SON), winter (DJF for the same year), and spring (MAM). In those cases a different threshold of 20 days of overlapping observations was applied. We note that we do not intend to investigate the errors at the seasonal scale but rather to study whether different seasons trigger different error correlation structures.

To estimate the spatial correlation scales, the pairwise correlations were grouped into bins of $100 \mathrm{~km}$ distance for towers and $10 \mathrm{~km}$ for aircraft data respectively (dist). Following the median for each bin was calculated, and a model similar to Eq. (3) was fitted but omitting the nugget effect variable:

$r=e^{-\frac{\text { dist }}{d}}$. 
The nugget effect could not be constrained simultaneously with the spatial correlation scale $d$ given the relatively coarse distance groups, the fast drop in the median correlation from 1 at 0 distance to small values for the first distance bin combined with somewhat variations at larger distances. Note that this difference between the spatial and the temporal correlation becomes obvious in the results Sect. 3 .

Confidence intervals for the estimated model parameters were computed based on the profile likelihood (Venzon and Moolgavkar, 1988) as implemented within the "confint" function from MASS package inside the $\mathrm{R}$ statistical language.

As aircraft fluxes cannot obviously be measured at the same time at different locations, given the relatively short flight duration (about $1 \mathrm{~h}$ ) we treated aircraft flux transect as instantaneous "snapshots" of the flux spatial pattern across a landscape, neglecting temporal variability that may have occurred during flight.

\subsection{Analysis of model-model differences}

We evaluate both model-data flux residuals and modelmodel differences in a sense of pairwise model comparisons, in order to assess whether model-model differences can be used as proxy for the prior uncertainty, assuming that models have independent prior errors. In order to minimise potential influence of the different spatial resolution between the models on the estimated correlation lengths, we compare pairs that have comparable spatial resolution. Such cases are VPRM50-ORCHIDEE and VPRM10-5PM. We choose VPRM10 as more representative to compare against 5PM as $5 \mathrm{PM}$ fluxes have also a resolution of $10 \mathrm{~km}$ (the main driver, MODIS radiation has the same resolution of $10 \mathrm{~km}$ for both models). Similar to the model-observation analysis, the statistical analysis gives a combined effect of both model errors. We assess the impact in the error structure between modelobservation and model-model comparisons caused by the observation error by adding a random measurement error to each model-model comparison. This error has the same characteristics as the observation error which is typically associated with eddy covariance observations; the error characteristics were derived from the paired observation approach (Richardson et al., 2008). Specifically, we implement the flux observation error as a random process (white noise) with a double-exponential probability density function. This can be achieved by selecting a random variable $u$ drawn from the uniform distribution in the interval $(-1 / 2,1 / 2)$ and then applying Eq. (5) to get a Laplace distribution (also referred to as the double exponential):

$x=\mu-\frac{\sigma}{\sqrt{2}} \cdot \operatorname{sgn}(u) \cdot \ln (1-2 \cdot|u|)$.

Here $\mu=0$ and $\sigma$ is the standard deviation of the double exponential. We compute the $\sigma$ according to Richardson et al. (2006) as

$\sigma=\alpha_{1}+\alpha_{2} \cdot|F|$

where $F$ is the flux and $\alpha_{1}, \alpha_{2}$ are scalars specific to the different vegetation classes. Lasslop et al. (2008) found that the autocorrelation of the half-hourly random errors is below 0.7 for a lag of $30 \mathrm{~min}$ and falls off rapidly for longer lag times. Thus we assume the standard deviation for hourly random errors to be comparable with the half-hourly errors. Hourly random errors specific for each reference model are generated for each site individually. With ORCHIDEE as reference with fluxes at 3-hourly resolution, a new ensemble of 3hourly random noise was generated with $\sigma$ for the 3-hourly errors modified (divided by the square root of 3 to be coherent with the hourly $\sigma$ ). As both modelled and observed fluxes share the same gaps, the random errors were aggregated to daily resolution, with gaps such to match those of observed fluxes. Finally the daily random errors were added to the modelled fluxes.

\section{Results}

\subsection{Model-data comparison for tower and aircraft fluxes}

Observed daily averaged NEE fluxes, for all ground sites and the full time series, yield a standard deviation of $3.01 \mu \mathrm{mol} \mathrm{m} \mathrm{m}^{-2} \mathrm{~s}^{-1}$, while the modelled fluxes were found to be less spatially varying and with a standard deviation of 2.84, 2.80, 2.53, and $2.64 \mu \mathrm{mol} \mathrm{m}^{-2} \mathrm{~s}^{-1}$ for VPRM10, VPRM1, ORCHIDEE, and 5PM respectively.

The residual distribution of the models defined as the difference between simulated and observed daily flux averages for the full year 2007 was found to have a standard deviation of $2.47,2.49,2.7$, and $2.25 \mu \mathrm{mol} \mathrm{m}^{-2} \mathrm{~s}^{-1}$ for VPRM10, VPRM1, ORCHIDEE, and 5PM respectively. Those values are only slightly smaller than the standard deviations of the observed or modelled fluxes themselves. This fact is in line with the generally low fraction of explained variance with $r$-square values of $0.31,0.27,0.12$, and 0.25 for VPRM10, VPRM1, ORCHIDEE, and 5PM respectively. When using site-specific correlations (correlations computed for each site, then averaged over all sites), the average fraction of explained variance increases to $0.38,0.36,0.35$, and 0.42 for VPRM10, VPRM1, ORCHIDEE, and 5PM respectively. Note that for deseasonalised time series (using a secondorder harmonic, not shown) the same picture emerges with increased averaged site-specific correlation compared to correlations using all sites. This indicates better performance for the models to simulate temporal changes (not only seasonal, but also synoptic) at the site level. Further, the differences between site-specific and overall $r$-square values indicate limitation of the models to reproduce observed spatial (site to site) differences. Figure 2 shows the correlation be- 


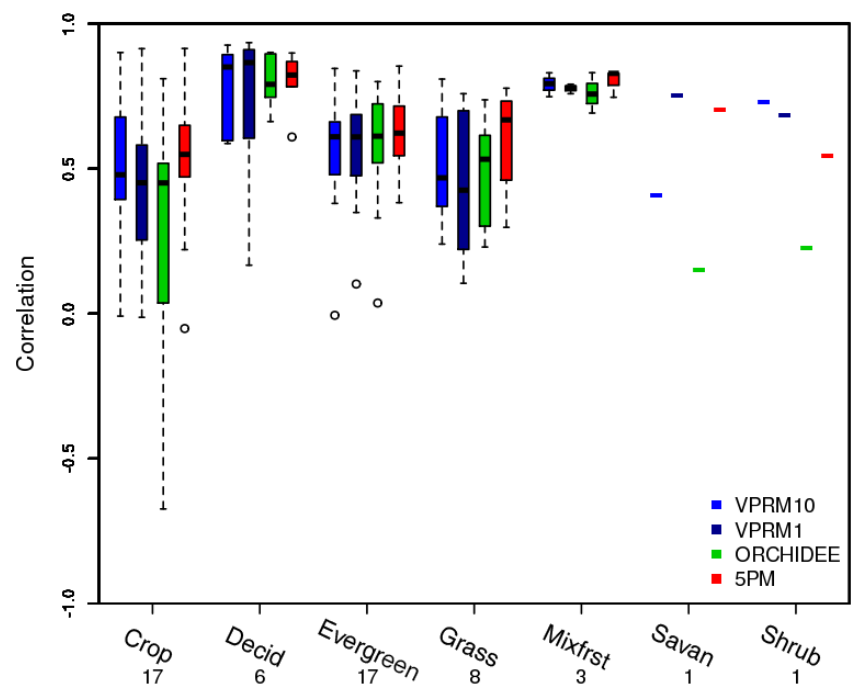

Figure 2. Box and whisker plot for site-specific correlation coefficients between modelled and observed daily fluxes as a function of the vegetation type. The numbers beneath the $x$ axis indicate the number of sites involved. The bottom and the top of the box denote the first and the third quartiles. The band inside the box indicates the central $50 \%$ and the line within is the median. Upper and lower line edges denote the maximum and the minimum values excluding outliers. Outliers are shown as circles.

tween modelled and observed daily fluxes as a function of the vegetation type characterising each site. All models exhibit a significant scatter of the correlation ranging from 0.9 for some sites to 0 or even negative correlation for some crop sites, with the highest correlation coefficients for deciduous and mixed forest.

The distribution is biased by $-0.07,0.26,0.92$, and $0.25 \mu \mathrm{mol} \mathrm{m}{ }^{-2} \mathrm{~s}^{-1}$ for VPRM10, VPRM1, ORCHIDEE, and 5PM respectively. Figure 3 shows the distribution of bias (defined as modelled-observed fluxes) for different vegetation types. Bias and standard deviation seem to depend on the vegetation type for all models, without a clear general pattern.

The temporal autocorrelation was calculated for modeldata residuals for each of the flux sites ("site data" in Fig. 4), but also for the full data set ("all-site" in Fig. 4). The all-site temporal autocorrelation structure of the residuals appears to have the same pattern for all models. It decays smoothly for time lags up to 3 months and then remains constant near to 0 or to some small negative values. The temporal autocorrelation increases again for time lags $>10$ months, which is caused by the seasonal cycle. These temporal autocorrelation results agree with the findings of Chevallier et al. (2012).

The exponentially decaying model in Eq. (3) was used to fit the data. At 0 separation time $(t=0)$ the correlogram value is 1 . However the correlogram exhibits a nugget effect (values ranging from 0.31 to 0.48 for the different models) as a consequence of an uncorrelated part of the error. For the

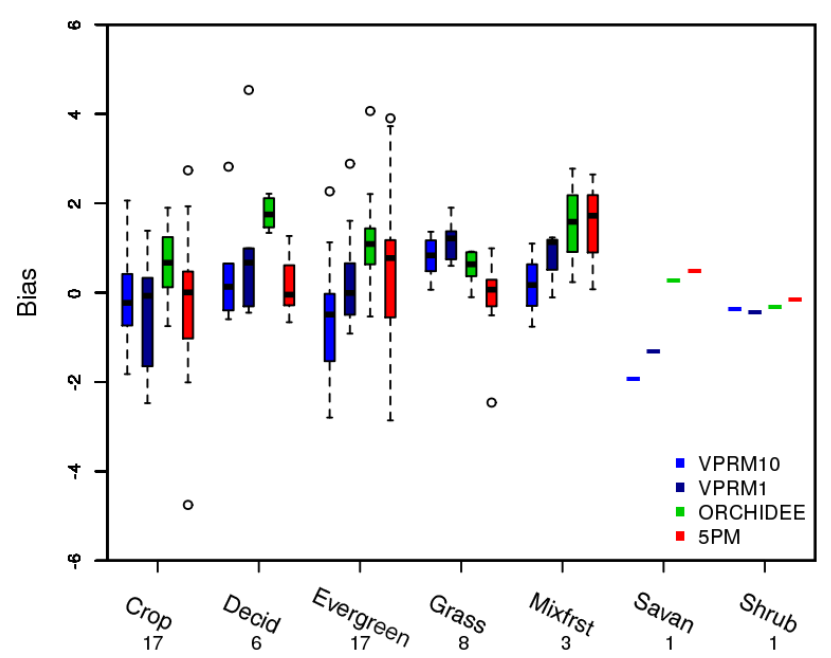

Figure 3. Box and whisker plot for the annual site-specific biases of the models differentiated by vegetation type. Units at $y$ axis are in $\mu \mathrm{mol} \mathrm{m} \mathrm{m}^{-2} \mathrm{~s}^{-1}$ (for conversion to $\mathrm{gC} \mathrm{m}^{-2} \mathrm{yr}^{-1}$ reported values in $y$ axis should be multiplied by 3787694 ).
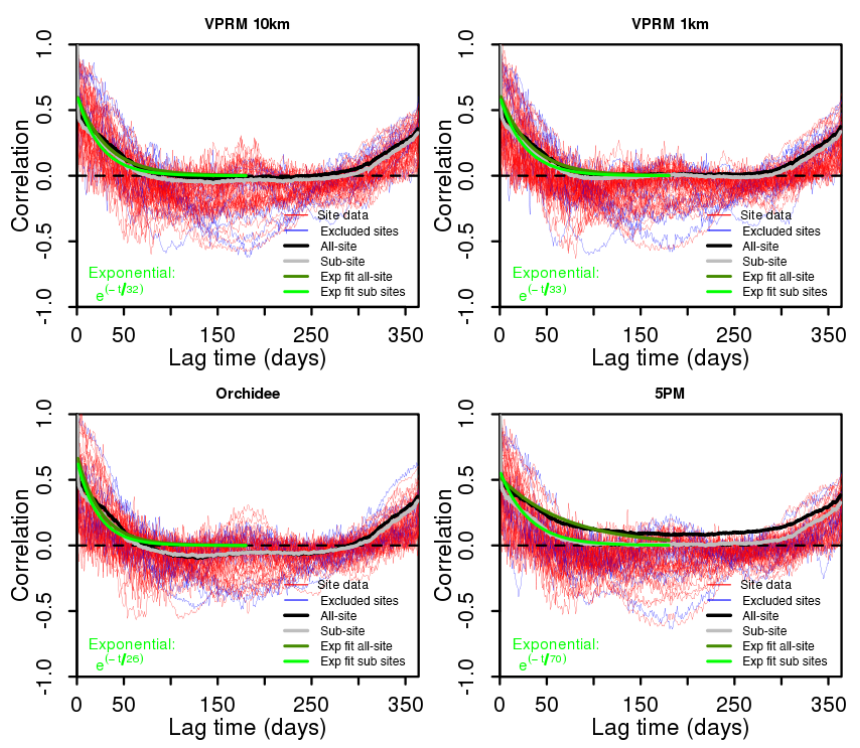

Figure 4. Temporal lagged autocorrelation from model-data daily averaged NEE residuals for all models. Thin red lines correspond to different sites, while the blue thin lines reveal the sites with a bias larger than $\pm 2.5 \mu \mathrm{mol} \mathrm{m} \mathrm{m}^{-2} \mathrm{~s}^{-1}$. The thick black line shows the all-site autocorrelation, and the thick grey line indicates the all-site autocorrelation but for a subset that excludes sites with large modeldata bias ("sub-site"). The dark green line is the all-site exponential fit, and the light green line shows the all-site autocorrelation excluding the sites with large bias. The exponential fits use lag times up to 180 days.

current analyses we fit the exponential model with an initial correlation different from 1 . The fit has a root mean square error ranging from 0.036 to 0.059 for the different biosphere models. The normalised root mean square error (RMSE) (i.e. 
RMSE divided by the range of the autocorrelation) results in values ranging from 0.061 to 0.092 , indicating relative errors in the fit of less than $10 \%$. The e-folding time (defined as the lag required for the correlation to decrease by a factor of e ( $63 \%$ of its initial value) ranged between 26 and 70 days for the different models (see Table 2). Specifically, for VPRM10 and VPRM1 the e-folding time is 32 and 33 days respectively (30-34 days within $95 \%$ confidence interval for both). Confidence intervals for the e-folding time were calculated by computing the confidence intervals of the parameter in the fitted model. For ORCHIDEE best fit was 26 days (2328 days within $95 \%$ confidence interval). In contrast, 5PM yields a significantly longer correlation time between 65 and 75 days (95\% confidence interval) with the best fit being 70 days.

For a number of sites a large model-data bias was found. In order to assess how the result depends on individual sites where model-data residuals are more strongly biased the analysis was repeated under exclusion of sites with an annual mean of model-data flux residuals larger than $2.5 \mu \mathrm{mol} \mathrm{m}{ }^{-2} \mathrm{~s}^{-1}$. This threshold value is roughly half of the most deviant bias. In total nine sites (CH-Lae, ES-ES2, FR-Pue, IT-Amp, IT-Cpz, IT-Lav, IT-Lec, IT-Ro2, PT-Esp) across all model-data residuals were excluded. From these sites, $\mathrm{CH}-\mathrm{Lae}$ appears to have serious problems related to the steep terrain, where the basic assumptions made for eddy covariance flux measurements are not applicable (Göckede et al., 2008). The rest of the sites are located in the Mediterranean region and suffer from summer drought according to the Köppen-Geiger climate classification map (Kottek et al., 2006); in those cases a large model-data bias is expected as existing models tend to have difficulties estimating carbon fluxes for drought-prone periods (Keenan et al., 2009). The model-data bias at those sites does not necessarily exceed the abovementioned threshold of $2.5 \mu \mathrm{mol} \mathrm{m}{ }^{-2} \mathrm{~s}^{-1}$ simultaneously for each individual model, but a larger bias than the average was detected. After exclusion of those sites the temporal correlation times were found to be between 33 and 35 days within $95 \%$ confidence interval for 5PM with the bestfit value being 34 days. The rest of the models had temporal e-folding times of 27,29, and 24 days (first row of Table 2), while the all-site correlation remains positive for lags $<76$, $<79$, and < 66 days for VPRM10, VPRM1, and ORCHIDEE respectively. Some weak negative correlations exist, with a minimum value of $-0.06,-0.02,-0.09$, and -0.005 for VPRM10, VPRM1, ORCHIDEE, and 5PM respectively.

The temporal correlation of differences between VPRM10 and aircraft flux measurements could be computed for time intervals up to 36 days (Fig. 5) corresponding to the duration of the campaign. The correlation shows an exponential decrease and levels off after about 25 days with an e-folding correlation time of 13 days (range of 10-16 days within the $95 \%$ confidence interval). Whilst the general behaviour is consistent with results obtained for VPRM-observation residuals for flux sites, the correlation time is 2 times smaller.

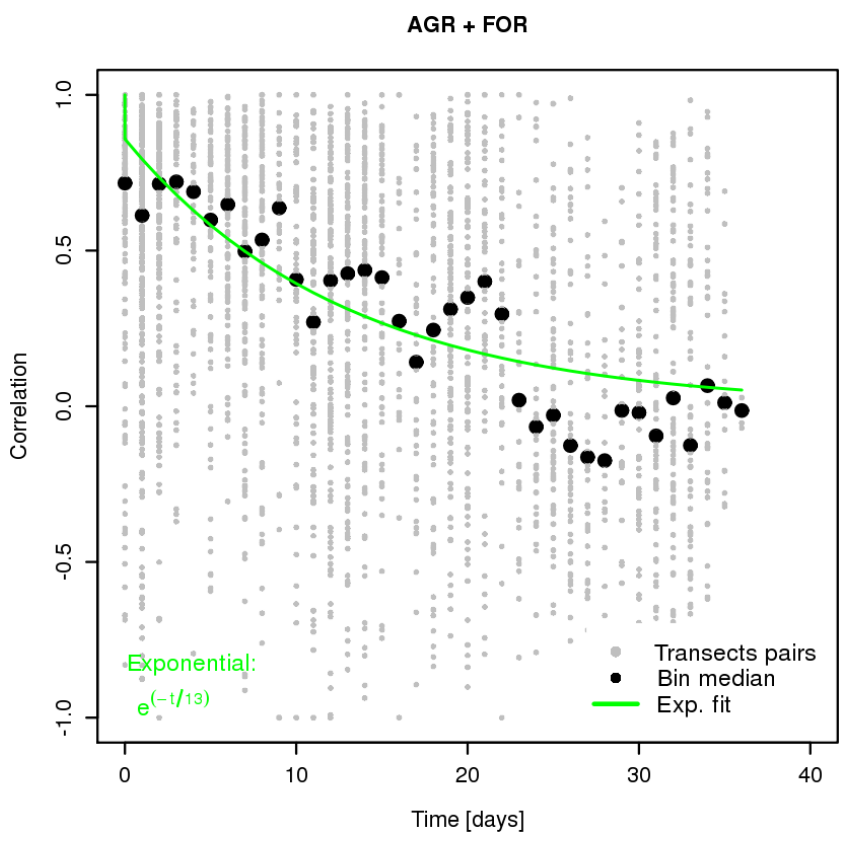

Figure 5. Temporal autocorrelation for VPRM10-aircraft NEE residuals. Black dots represent individual flux transects pairs sampled at different times as function of time separation. Black circles represent daily-scale binned data.

Regarding spatial error correlations, results for all models show a dependence on the distance between pairs of sites. The median correlation drops within very short distances (Fig. 6). Fitting the simple exponentially decaying model (Eq. 4) to the correlation as a function of distance we find an e-folding correlation length $d$ of 40,37,32, and $31 \mathrm{~km}$ with a RMSE of $0.14,0.09,0.05$, and 0.07 for VPRM10, VPRM1, ORCHIDEE, and 5PM respectively. The normalised RMSE is found to have values ranging from 0.05 to 0.084 indicating relative errors of the fit less than $9 \%$. Spatial correlation scales are also computed for a number of different data selections (cases) in addition to the standard case shown in Fig. 6 (case S): using only pairs with at least 150 overlapping days of non-missing data (case $\mathrm{S}^{*}$ ), using only pairs with identical PFT (case I), using only pairs with different PFT (case D), and using only pairs with at least 150 overlapping days for the D and I cases (cases $D^{*}, I^{*}$ ). The results for these cases are summarised in Fig. 7. Also $95 \%$ confidence intervals were computed, and the spread spatial correlation was found to be markedly more critical than for the time correlations. Note that for some cases the 2.5 percentile (the lower bound of the confidence interval) hit the lower bound for correlation lengths $(0 \mathrm{~km})$. The e-folding correlation lengths are similar for each of the models: this also means that no dependence on the spatial resolution was detectable. Further, we examined also the spatial autocorrelation from VPRM50data residuals with no significant difference compared to previous results. 
Table 2. Annual temporal autocorrelation times in days, from model-data and model-model residuals. The number within the brackets shows the correlation times when excluding sites with large model-data bias from the analysis.

\begin{tabular}{lrrrr}
\hline Reference & VPRM10 (days) & VPRM1 (days) & ORCHIDEE (days) & 5PM (days) \\
\hline OBSERVATION & $32(27)$ & $33(29)$ & $26(24)$ & $70(34)$ \\
VPRM50 & - & - & $28(28)$ & $52(46)$ \\
VPRM10 & - & - & - & $131(100)$ \\
ORCHIDEE & - & - & - & $38(32)$ \\
5PM & - & - & - & - \\
\hline
\end{tabular}
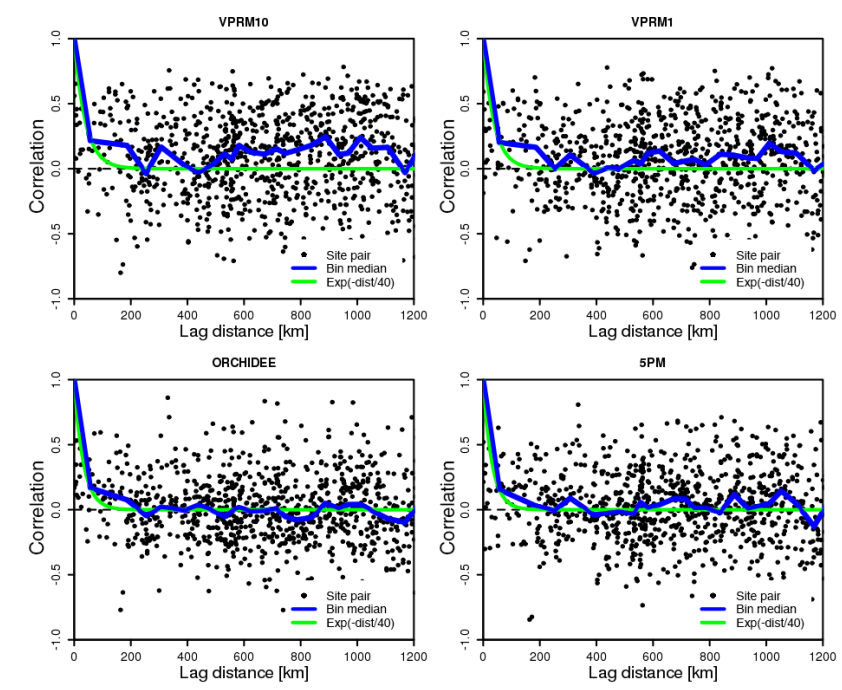

Figure 6. Distance correlogram for the daily net ecosystem exchange (NEE) residuals using all sites. Black dots represent the different site pairs; the blue line represents the median value of the points per $100 \mathrm{~km}$ bin and the green an exponential fit. Results are shown for residuals of VPRM at a resolution of 10 (top left) and $1 \mathrm{~km}$ (top right), ORCHIDEE (bottom left), 5PM (bottom right).

Interestingly, if we restrict the analysis to pairs with at least 150 overlapping days between site pairs, larger correlation scales are found (case $S^{*}$ in Fig. 7). Considering only pairs with different PFT (case D), consistently, all efolding correlation lengths are found to be smaller compared to the standard case (S). This is expected to a certain degree, as model errors should be more strongly correlated between sites with similar PFTs than between sites with different PFTs. By considering only pairs within the same vegetation type (case I) we observe a significant increase of the e-folding correlation length relative to case $\mathrm{S}$ for VPRM at 10 and $1 \mathrm{~km}$ resolution to values of $432 \mathrm{~km}$ and $305 \mathrm{~km}$ respectively. The ORCHIDEE and 5PM models show some (although not significant) increase in e-folding correlation length. Restricting again the analysis to pairs with at least 150 overlapping days for the $\mathrm{D}$ and I cases $\left(\mathrm{D}^{*}, \mathrm{I}^{*}\right)$ we observe an increase of the e-folding correlation lengths that is, however, significant only for VPRM at 10 and $1 \mathrm{~km}$.

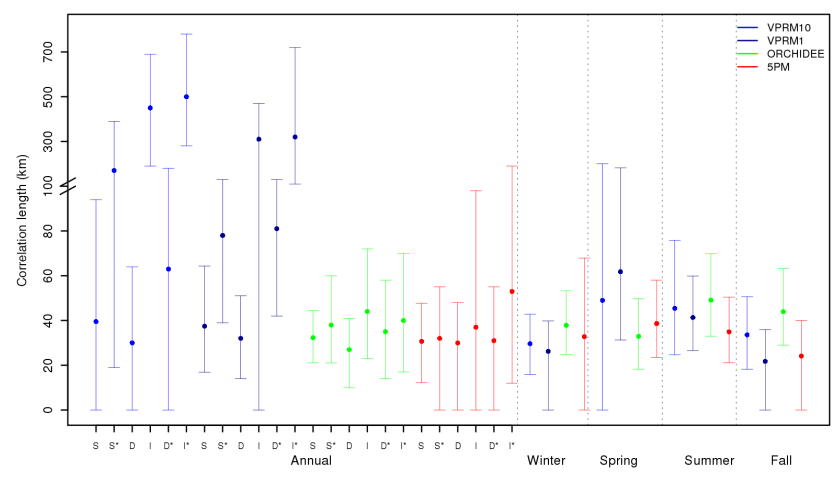

Figure 7. Annual and seasonal e-folding correlation length of the daily averaged model-data NEE residuals for VPRM at 10 and $1 \mathrm{~km}$ resolution, ORCHIDEE and 5PM. S refers to the standard case where all pairs were used, D refers to the case where only pairs with different vegetation types were used, I denotes the case in which only pairs with identical vegetation type were considered, and ${ }^{*}$ denotes that in addition 150 days of common non-missing data are required for each pair of sites. The dot represents the best-fit value when fitting the exponential model. The upper and the lower edge of the error bars show the 2.5 and 97.5 percentiles of the length value. Note the scale change in the $y$ axis at $100 \mathrm{~km}$.

Seasonal dependence of the e-folding correlation lengths for at least 20 overlapping days per season and for all-site pairs is also shown in Fig. 7. VPRM showed somewhat longer correlation lengths during spring and summer, ORCHIDEE had the largest lengths occurring during summer and autumn, and 5PM e-folding correlation lengths show slightly enhanced values during spring and summer. However, none of these seasonal differences are significant with respect to the $95 \%$ confidence interval.

The spatial error correlation between VPRM10 model and aircraft fluxes measured during May-June along continuous transects at forest and agriculture land use (Fig. 8) shows an exponential decay up to the maximum distance that was encompassed during flights (i.e. $70 \mathrm{~km}$ ). Of note is that only two measurements were available at $60 \mathrm{~km}$ distance and none for larger distances making it difficult to identify where the asymptote lies. Nevertheless, fitting the decay model (Eq. 4) leads to $d=35 \mathrm{~km}(26-46 \mathrm{~km}$ within the $95 \%$ confidence interval), which is in good agreement with the spatial corre- 


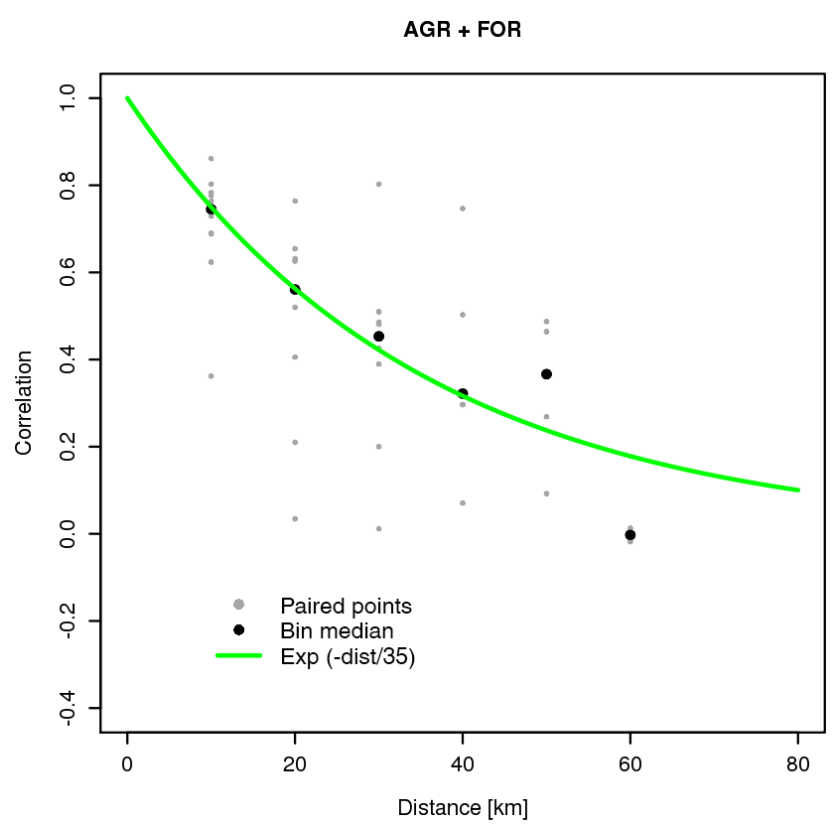

Figure 8. Distance correlogram between VPRM10 and aircraft NEE measurements. Black dots represents the different aircraft grid points pairs; black circles represent $10 \mathrm{~km}$ scale binned data.

lation scale derived for VPRM10 using flux sites during both spring and summer (Fig. 7).

\subsection{Model-model comparison}

We investigate the model-model error structure of NEE estimates by replacing the observed fluxes which were used as reference, with simulated fluxes from all the biosphere models. Note that for consistency with the model-data analysis, the simulated fluxes contained the same gaps as the observed flux time series. The e-folding correlation time is found to be slightly larger compared to the model-data correlation times, for most of the cases. An exception is the 5PM-VPRM10 pair which produced remarkably larger correlation time (Table 2). Specifically, VPRM50-ORCHIDEE and VPRM10-5PM residuals show correlation times of 28 days (range between 24 and 32 days within $95 \%$ confidence interval) and 131 (range between 128 and 137 days within $95 \%$ confidence interval) respectively. Significantly different e-folding correlation times are found for VPRM50-5PM compared to VPRM10-5PM with correlation times of 52 days (range between 49 and 56 days within $95 \%$ confidence interval). Repeating the analysis excluding sites with residual bias larger than $2.5 \mu \mathrm{mol} \mathrm{m}{ }^{-2} \mathrm{~s}^{-1}$, correlation times of 28 and 100 days for VPRM50-ORCHIDEE and VPRM105PM are found respectively. If we use the ORCHIDEE-5PM pair, the e-folding correlation time is 38 days (range between 35 and 41 days within $95 \%$ confidence interval).

Although the e-folding correlation times show only minor differences compared to the model-data residuals, this

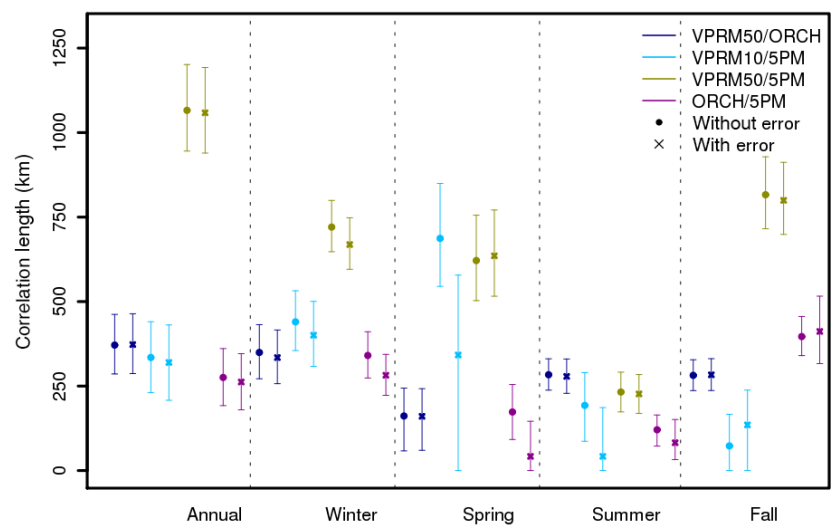

Figure 9. Annual and seasonal e-folding correlation length for an ensemble of daily averaged NEE differences between two models without (filled circle) and with random measurement errors added to the modelled fluxes used as reference (crosses). The symbols represents the best-fit value when fitting the exponential model, and the upper and lower edge of the error bars show the 2.5 and 97.5 percentiles of the correlation length. The first acronym at the legend represents the model used as reference and the second the model which was compared with. Note that for the VPRM10/VPRM1 case during spring (with and without random error), the 97.5 percentile of the length value exceeds the $y$ axis and has a value of 1073 , $1626 \mathrm{~km}$ respectively.

is not the case for the spatial correlation lengths (Fig. 9). The standard case (S) was applied for the annual analysis, with no minimum number of days with overlapping nonmissing data for each site within the pairs. Taking VPRM50 as reference, much larger e-folding correlation lengths of $371 \mathrm{~km}$ with a range of $286-462 \mathrm{~km}$ within $95 \%$ confidence interval yielded for VPRM50-ORCHIDEE comparisons, and $1066 \mathrm{~km}$ for VPRM50-5PM were found. However, VPRM10-5PM analysis, which is also considered appropriate in terms of the spatial resolution compatibility contrary to the VPRM50-5PM pair, is in good agreement with VPRM50-ORCHIDEE spatial scale (230-440 km range within $95 \%$ confidence interval with the best fit being $335 \mathrm{~km}$ ). With ORCHIDEE as reference, the e-folding correlation length for the ORCHIDEE-5PM comparison is $276 \mathrm{~km}$ with a range of $183-360 \mathrm{~km}$ within $95 \%$ confidence interval. However the later correlation length might be affected by the different spatial resolution as the difference between VPRM10 and VPRM50 against 5PM suggests. Seasonal e-folding correlation lengths, using a minimum of 20 days overlap in the site-pairs per season (Fig. 9), are also significantly larger compared with those from the model-data analysis.

When we add the random measurement error to the modelled fluxes used as reference (crosses in Fig. 9), we observe only slight changes in the annual e-folding correlation lengths, without a clear pattern. The correlation lengths show a random increase or decrease but limited up to $6 \%$. Interest- 


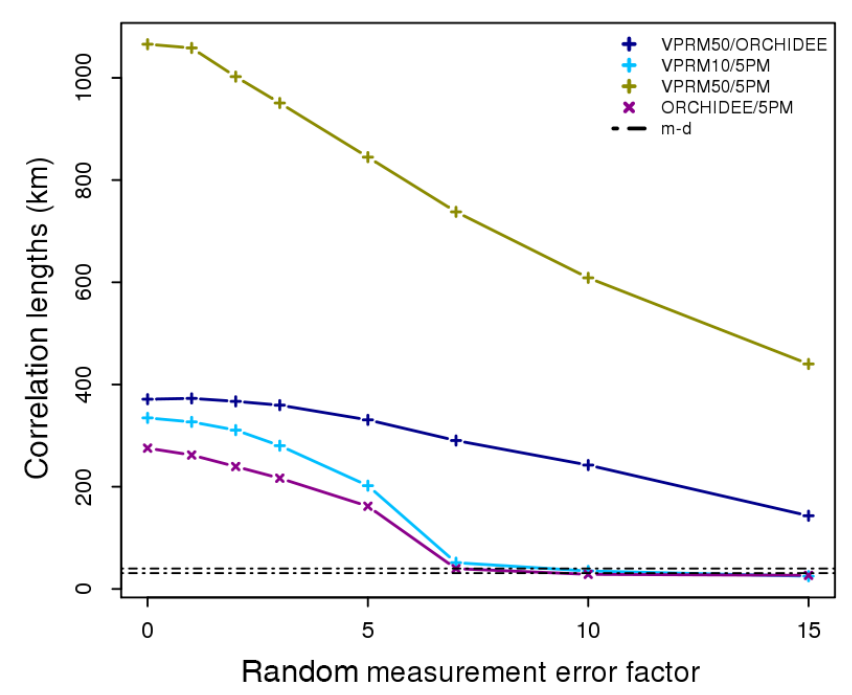

Figure 10. Annual e-folding correlation lengths as a function of the factor used for scaling the random measurement error, for all model-model combinations. The black dot-dash lines reveal the range of the spatial correlation lengths generated from the modeldata comparisons.

ingly, the seasonal e-folding correlation lengths for most of the cases show a more clear decrease. For example, the correlation length of the VPRM10-5PM residuals during winter decreases by $22 \%$ or even more for spring season. Despite this decrease, the e-folding seasonal correlation lengths remain significantly larger in comparison to those from the model-data analysis. Overall, all models when used as reference show the same behaviour with large e-folding correlation lengths that mostly decrease slightly when the random measurement error is included. Although the random measurement error was added as "missing part" to the modelled fluxes to better mimic actual flux observations, it did not lead to correlation lengths similar to those from the modeldata residual analysis. To investigate whether a larger random measurement error could cause spatial correlation scales in model-model differences, we repeated the analysis with artificially increased random measurement error (multiplying with a factor between 1 and 15). Only for very large random measurement errors did the model-model e-folding correlation lengths start coinciding with those of the model-data residuals (Fig. 10).

\section{Discussion and conclusions}

We analysed the error structure of a priori NEE uncertainties derived from a multi-model-data comparison by comparing fluxes simulated by three different vegetation models to daily averages of observed fluxes from 53 sites across Europe, categorised into seven land cover classes. The different models showed comparable performance with respect to reproduc- ing the observed fluxes; we found mostly insignificant differences in the mean of the residuals (bias) and in the variance. Site-specific correlations between simulated and observed fluxes are significantly higher than overall correlations for all models, which suggest that the models struggle with reproducing observed spatial flux differences between sites. Furthermore, the site-specific correlations reveal a large spread even within the same vegetation class, especially for crops (Fig. 2). This is likely due to the fact that none of the models uses a specific crop model that differentiates between the different crop types and their phenology. The models using remotely sensed vegetation indices (VPRM and 5PM) better capture the phenology; ORCHIDEE is the only model that differentiates between $C_{3}$ and $C_{4}$ plants but shows the largest spread in correlation for the crop. Differences in correlations between the different vegetation types were identified for all the biosphere models; however it must be noted that the number of sites per vegetation type is less than 10 except for crop and evergreen forests.

Model-data flux residual correlations were investigated to give insights regarding prior error temporal scales which can be adopted by atmospheric inversion systems. Whilst fluxes from ORCHIDEE model are at much coarser resolution compared to the representative area from the flux measurements, VPRM1 fluxes $(1 \mathrm{~km}$ resolution and only the meteorology at $25 \mathrm{~km}$ ) are considered appropriate for the comparisons. Despite the scale mismatch, results are in good agreement across all model-data pairs.

Exponentially decaying correlation models are a dominant technique among atmospheric inverse studies to represent temporal and spatial flux autocorrelations (Rödenbeck et al., 2009; Broquet et al., 2011, 2013). However, regarding the temporal error structure we need to note the weakness of this model to capture the slightly negative values at $2-10$ months lags and, more importantly, the increase in correlations for lag times larger than about 10 months. Error correlations were parameterized differently by Chevalier et al. (2012) where the prior error was investigated without implementing it to atmospheric inversions. Polynomial and hyperbolic equations were used to fit temporal and spatial correlations respectively. Nevertheless, we use here e-folding lengths not only for their simplicity in describing the temporal correlation structure with a single number but also because this error model ensures a positive definite covariance matrix (as required for a covariance). This is crucial for atmospheric inversions as otherwise negative, spatially and temporally integrated uncertainties may be introduced. In addition it can keep the computational costs low, because the hyperbolic equation has significant contributions from larger distances: for the case of the VPRM1 model, at $200 \mathrm{~km}$ distance the correlation according to Chevallier et al., hyperbolic equation is 0.16 compared to 0.004 for the exponential model. As a consequence, more non-zero elements are introduced to the covariance matrix, which increases computational costs in the inversion systems. Using the same hyperbolic equation 
for the spatial correlation, $d$ values of $73,39,12$, and $20 \mathrm{~km}$ were found with a RMSE of 0.11, 0.07, 0.05, and 0.07 for VPRM10, VPRM1, ORCHIDEE, and 5PM respectively. A similar RMSE was found when using the exponential $(0.14$, $0.09,0.05$, and 0.07 ), indicating similar performance of both approaches with respect to fitting the spatial correlation.

Autocorrelation times were found to be in line with findings of Chevallier et al. (2012). The model-data residuals were found to have an e-folding time of 32 and 26 days for VPRM and ORCHIDEE respectively and 70 days for 5PM. This significant difference appears to have a strong dependence on the set of sites used in the analysis. Excluding nine sites with large residual bias, the autocorrelation time from the 5PM-data residuals drastically decreased and became coherent with the times of the other biosphere models. The allmodels and all-site autocorrelation time was found to be 39 days, which reduces to 30 days (28-31 days within $95 \%$ confidence interval), when excluding the sites with large residual bias, coherent with the single model times. From the modelmodel residual correlation analysis, the correlation time appear to be consistent with the above-mentioned results and lies between 28 and 46 days for most of the ensemble members. However model-model pairs consisting of the VPRM and 5PM models produced larger times up to 131 days; omitting sites with large residual biases this is reduced to 100 days (99-105 days within $95 \%$ confidence interval). This finding could be attributed to the fact that despite the conceptual difference between those models, they do have some common properties. Both models were optimized against eddy covariance data although for different years (2005 and 2007 respectively), while no eddy covariance data were used for the optimisation of ORCHIDEE. In addition, VPRM and 5PM both use data acquired from MODIS, although they estimate photosynthetic fluxes by using different indices of reflectance data. Summarising the temporal correlation structure, it appears reasonable to (a) use the same error correlation in atmospheric inversions regardless of which biospheric model is used prior or (b) use an autocorrelation length of around 30 days.

Only weak spatial correlations for model-data residuals were found, comparable to those identified by Chevallier et al. (2012) that were limited to short lengths up to $40 \mathrm{~km}$ without any significant difference between the biospheric models (31-40 km). Hilton et al. (2012) estimated spatial correlation lengths of around $400 \mathrm{~km}$. However, we note that significant differences exist between this study and Hilton et al. (2012) regarding the methods that were used and the landscape heterogeneity of the domain of interest. With respect to the first aspect the time resolution is much coarser (seasonal averaged flux residuals) compared to the daily averaged residuals used here. Furthermore spatial bins of $300 \mathrm{~km}$ were used for the autocorrelation analysis, which is far larger than the approximate bin width of $100 \mathrm{~km}$ that were used in our study. Regarding the second aspect North America has a more homogenous landscape compared to the European domain. The scales for each ecosystem type (e.g. forests, agricultural land) are drastically larger than those in Europe as can be seen from MODIS retrievals (Friedl et al., 2002).

Although the estimated spatial scales are shorter than the spatial resolution that we are solving for $(100 \mathrm{~km}$ bins $)$, the autocorrelation analysis of aircraft measurements made during CERES supports the short-scale correlations. These measurements have the advantage of providing continuous spatial flux transects along specific tracks that were sampled routinely (in this case over period of 36 days at various times of the day), thus also resolving flux spatial variability at small scales, where pairs of eddy covariance sites may not be sufficiently close. However, aircraft surveys are necessarily sporadic in time. Of note is that the eddy covariance observation error has no significant impact on the error structure, as the addition of an observation error to the analysis of model-model differences had only minor influence on the error structure. We note that the current analysis focuses to daily timescale and therefore the error statistics with respect to the estimated spatial and temporal e-folding correlation lengths are valid for such scales.

Model-data residual e-folding correlation lengths show a clear difference between the cases where pairs only with different (D) or identical (I) PFT were considered, with the latter resulting in longer correlation lengths but only identified for the VPRM model at both resolutions. The D case has slightly shorter lengths for all models than the standard case (S). One could argue that as VPRM uses PFT-specific parameters that were optimized against 2005 observations, the resulting PFT-specific bias could lead to longer spatial correlations. However, ORCHIDEE and 5PM also show comparable biases (Fig. 3), although long correlation scales were not found. Moreover we repeated the spatial analysis after subtracting the PFT-specific bias from the fluxes, and the resulting correlation lengths showed no significant change. The impact of data gaps was also investigated by setting a threshold value of overlapping observations between site pairs. Setting this to 150 days results in an increase for the $S$ case up to $60 \mathrm{~km}$ but only for the VPRM model. For the D and I cases when setting the same threshold value $\left(\mathrm{D}^{*}\right.$ and $\left.\mathrm{I}^{*}\right)$ we only found an insignificant increase, indicating that data gaps are hardly affecting the D and I cases. These findings suggest that high-resolution diagnostic models might be able to highlight the increase of the spatial correlation length between identical PFTs vs. different PFTs. Note that the Chevallier et al. (2012) study concluded that assigning vegetation-typespecific spatial correlations is not justified, based on comparisons of eddy covariance observations with ORCHIDEE simulated fluxes. The current study could not further investigate this dependence, as the number of pairs within a distance bin is not large enough for statistical analyses when using only sites within the same PFT. With respect to the seasonal analysis, spatial correlations are at the same range among all models and seasons. Although in some cases (VPRM10 and VPRM1 spring) the scales are larger, they suffer from large 
uncertainties. Hence, implementing distinct and seasonally dependent spatial correlation lengths in inversion systems cannot be justified.

The analysis of model-model differences did not reproduce the same spatial scales as those from the model-data differences, but instead spatial e-folding correlation lengths were found to be dramatically larger. Adding a random measurement error to the modelled fluxes used as reference slightly reduced the spatial correlation lengths to values ranging from 278 to $1058 \mathrm{~km}$. Even when largely inflating the measurement error, the resulting spatial correlation lengths (Fig. 10) still do not approach those derived from modeldata residuals. Only when the measurement error is scaled up by a factor of 8 or larger (which is quite unrealistic as this corresponds to a mean error of $1.46 \mu \mathrm{mol} \mathrm{m}{ }^{-2} \mathrm{~s}^{-1}$ or larger, which is comparable to the model-data mismatch where a standard deviation of around $2.5 \mu \mathrm{mol} \mathrm{m} \mathrm{m}^{-2} \mathrm{~s}^{-1}$ was found), the e-folding correlation lengths are consistent with those based on model-data differences. Whilst the EC observations are sensitive to a footprint area of about $1 \mathrm{~km}^{2}$, the model resolution is too coarse to capture variations at such a small scale. This local uncorrelated error has not been taken into account by the analysis of model-data residuals as the error model could not be fitted with a nugget term included, favouring therefore smaller correlation scales. The analysis of differences between two coarser models does not involve such a small-scale component, thus resulting in larger correlation scales. This would suggest that for inversion studies targeting scales much larger than the eddy covariance footprint scale, the statistical properties of the prior error should be derived from the model-model comparisons.

The large e-folding correlation lengths yielded from this model-model residual analysis suggest that the models are more similar to each other than to the observed terrestrial fluxes, at least on spatial scales up to a few hundred kilometres regardless of their conceptual differences. This might be expected to some extent due to elements that the models share. Respiration and photosynthetic fluxes are strongly driven by temperature and downward radiation respectively and those meteorological fields have significant commonalities between the different models. VPRM and 5PM both use temperature and radiation from ECMWF analysis and short-term forecasts. Also the WFDEI temperature and radiation fields used in ORCHIDEE are basically from the ERAInterim reanalysis, which also involves the integrated forecasting system (IFS) used at ECMWF (Dee et al., 2011). Regarding the vegetation classification all models are site specific and therefore are using the same PFT for each corresponding grid cell. Photosynthetic fluxes are derived with the use of MODIS indices in VPRM (EVI and LSWI) and in 5PM (LAI and albedo).

Using full flux fields from the model ensemble (rather than fluxes at specific locations with observation sites only) to assess spatial correlations in model-model differences is not expected to give significantly different results, as the sites are representative for quite a range of geographic locations and vegetation types within the domain investigated here.

The current study intended to provide insight on the error structure that can be used for atmospheric inversions. Typically, inversion systems have a pixel size ranging from 10 to $100 \mathrm{~km}$ for regional and continental inversions, and as large as several degrees (hundreds of kilometres) for global inversions. If a higher-resolution system assumes such small-scale correlations (as those found in the current analysis), in the covariance matrix, this leads to very small prior uncertainties when aggregating over large areas and over longer time periods. To aggregate the uncertainty to large temporal and spatial scales, we used the following equation (after Rodgers, 2000):

$U a=u \times Q_{\mathrm{c}} \times u^{T}$,

where " $\times$ " denotes matrix multiplication, $Q_{\mathrm{c}}$ is the prior error covariance matrix, and $u$ a scalar operator that aggregates the full covariance to the target quantity (e.g. domainwide and full year). For example, with a $30 \mathrm{~km}$ spatial and a 40-day temporal correlation scale, annually and domainwide (Fig. 1) aggregated uncertainties are around $0.06 \mathrm{GtC}$. This is about a factor of 10 smaller than uncertainties typically used e.g. in the Jena inversion system (Rödenbeck et al., 2005). This value is also 8 times smaller when comparing it to the variance of the signal between 11 global inversions reported in Peylin et al. (2013) which was found to be $0.45 \mathrm{GtC} \mathrm{yr}^{-1}$, proving that the aggregated uncertainties are unrealistically small. In addition, the aggregated uncertainties using the VPRM10-ORCHIDEE error structure (32 days and $320 \mathrm{~km}$ temporal and spatial correlation scales) are found to be $0.46 \mathrm{GtC} \mathrm{yr}^{-1}$ which is also much smaller than the difference between VPRM10 $\left(\mathrm{NEE}=-1.45 \mathrm{GtC} \mathrm{yr}^{-1}\right)$

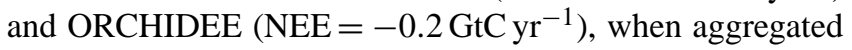
over the domain shown in Fig. 1. Although this analysis does capture the dominating spatiotemporal correlation scale in the error structure, it fails in terms of the error budget, suggesting that also other parts of the error structure are important as well. Therefore additional degrees of freedom (e.g. for a large-scale bias) need to be introduced in the inversion systems to fully describe the error structure.

Whilst temporal scales found from this study have already been used in inversion studies, this is not the case to our best knowledge for the short spatial scales. The impact of the prior error structure derived from this analysis, on posterior flux estimates and uncertainties will be assessed in a subsequent paper. For that purpose, findings from this study are currently implemented in three different regional inversion systems aiming to focus on network design for the ICOS atmospheric network.

Acknowledgements. The research leading to these results has received funding from the European Community's Seventh Framework Program ([FP7/2007-2013]) under grant agreement 
no. 313169 (ICOS-INWIRE) and 283080 (GEOCARBON). The EC data used in this study were funded by the European Community's Sixth and Seventh Framework programs and by national funding agencies. The following sites are listed, sorted by project/funding agency: BE-Bra, BE-Lon, BE-Vie, CH-Lae, CHOe1, CH-Oe2, CZ-BK1, DE-Geb, DE-Gri, DE-Hai, DE-Kli, DETha, DK-Lva, ES-ES2, ES-LMa, FI-Hyy, FR-Fon, FR-Hes, FRLBr, FR-Lq1, FR-Lq2, FR-Pue, IT-SRo, NL-Dij, NL-Loo, PT-Esp, PT-Mi2, SE-Kno, SE-Nor, SE-Sk1, SK-Tat, UK-AMo, and UK$\mathrm{EBu}$ are funded by CarboEuropeIP (grant agreement no. GOCECT-2003-505572); UK-AMo and UK-EBu are also co-funded by EU FP7 ECLAIRE project and NERC-CEH; IT-BCi, IT-Cas, ITLav, and IT-LMa are funded by Carboltaly (IT-FISR); IT-Amp, ITCol, IT-Cpz, IT-MBo, IT-Ren, and IT-Ro2 are co-funded by CarboEuropeIP and by CarboItaly; $\mathrm{CH}-\mathrm{Cha}, \mathrm{CH}-\mathrm{Dav}$, and $\mathrm{CH}-\mathrm{Fru}$ are co-funded by CarboExtreme (grant agreement no. 226701) and GHG-Europe (grant agreement no. 244122); ES-Agu is funded by GHG-Europe; FR-Mau is co-funded by CNRM/GAME (METEOFRANCE, CNRS), CNES, and ONERA. We also acknowledge funding agencies for the sites FR-Aur, FR-Avi, and HU-Mat.

The authors would like to thank Anna Michalak and the anonymous reviewer whose insightful comments helped the development of the manuscript.

The article processing charges for this open-access publication were covered by the Max Planck Society.

Edited by: T. Keenan

\section{References}

Albergel, C., Calvet, J.-C., Gibelin, A.-L., Lafont, S., Roujean, J.L., Berne, C., Traullé, O., and Fritz, N.: Observed and modelled ecosystem respiration and gross primary production of a grassland in southwestern France, Biogeosciences, 7, 1657-1668, doi:10.5194/bg-7-1657-2010, 2010.

Allard, V., Ourcival, J.-M., Rambal, S., Joffre, R., and Rocheteau, A.: Seasonal and annual variation of carbon exchange in an evergreen Mediterranean forest in southern France, Glob. Change Biol., 14, 714-725, 2008.

Ammann, C., Spirig, C., Leifeld, J., and Neftel, A.: Assessment of the nitrogen and carbon budget of two managed grassland fields, Agriculture, Ecosyst. Environ., 133, 150-162, 2009.

Aubinet, M., Grelle, A., Ibrom A., Rannik Ü., Moncrieff J., Foken T., Kowalski A.-S., Martin P.-H., Berigier P., Bernhofer C., Clement R., Elbers J., Granier A., Grünwald T., Morgenstern K., Pilegaard K., Rebmann C., Snijders W., Valentini, R., and Vesala, T.: Estimates of the Annual Net Carbon and Water Exchange of Forests: The EUROFLUX Methodology, Adv. Ecol. Res., 30, 113-175, 2000.

Aubinet, M., Chermanne, B., Vandenhaute, M., Longdoz, B., Yernaux, M., and Laitat, E.: Long term carbon dioxide exchange above a mixed forest in the Belgian Ardennes, Agr. Forest Meteorol., 108, 293-315, 2001.

Baldocchi, D., Falge, E., Gu, L., Olson, R., Hollinger, D., Running, S., Anthoni, P., Bernhofer, C., Davis, K., Evans, R., Fuentes, J., Goldstein, A., Katul, G., Law, B., Lee, X., Malhi, Y., Meyers, T., Munger, W., Oechel, W., Paw, K. T., Pilegaard, K., Schmid, H.
P., Valentini, R., Verma, S., Vesala, T., Wilson, K., and Wofsy, S.: A new tool to study the temporal and spatial variability of ecosystem-scale carbon dioxide, water vapor, and energy flux densities, Bull. Am. Meteorol. Soc., 82, 2415-2434, 2001.

Barcza, Z., Weidinger, T., Csintalan., Zs., Dinh, N.-Q., Grosz, B., and Tuba, Z.: The carbon budget of a semiarid grassland in a wet and a dry year in Hungary, Agr. Ecosyst. Environ., 121, 21-29, 2007.

Bousquet, P., Ciais, P., Peylin, P., Ramonet, M., and Monfray, P.: Inverse modeling of annual atmospheric $\mathrm{CO}_{2}$ sources and sinks: 1 . Method and control inversion, J. Geophys. Res.,-Atmos. (19842012), 104, 26161-26178, 1999.

Broquet, G., Chevallier, F., Rayner, P., Aulagnier, Cé., Pison, I., Ramonet, M., Schmidt, M., Vermeulen, A.-T., and Ciais, P.: A European summertime $\mathrm{CO}_{2}$ biogenic flux inversion at mesoscale from continuous in situ mixing ratio measurements, J. Geophys. Res.Atmos. (1984-2012), 116, D23303, doi:10.1029/2011JD016202, 2011.

Broquet, G., Chevallier, F., Bréon, F.-M., Kadygrov, N., Alemanno, M., Apadula, F., Hammer, S., Haszpra, L., Meinhardt, F., Morguí, J. A., Necki, J., Piacentino, S., Ramonet, M., Schmidt, M., Thompson, R. L., Vermeulen, A. T., Yver, C., and Ciais, P.: Regional inversion of $\mathrm{CO}_{2}$ ecosystem fluxes from atmospheric measurements: reliability of the uncertainty estimates, Atmos. Chem. Phys., 13, 9039-9056, doi:10.5194/acp-13-9039-2013, 2013.

Carouge, C., Bousquet, P., Peylin, P., Rayner, P. J., and Ciais, P.: What can we learn from European continuous atmospheric $\mathrm{CO}_{2}$ measurements to quantify regional fluxes - Part 1: Potential of the 2001 network, Atmos. Chem. Phys., 10, 3107-3117, doi:10.5194/acp-10-3107-2010, 2010.

Casals, P., Lopez-Sangil, L., Carrara., A., Gimeno, C., and Nogues, S.: Autotrophic and heterotrophic contributions to short-term soil $\mathrm{CO}_{2}$ efflux following simulated summer precipitation pulses in a Mediterranean dehesa, Global Biogeochem. Cy., 25, GB3012, doi:10.1029/2010GB003973, 2011.

Chevallier, F., Viovy, N., Reichstein, M., and Ciais, P.: On the assignment of prior errors in Bayesian inversions of $\mathrm{CO}_{2}$ surface fluxes, Geophys. Res. Lett., 33, L13802, doi:10.1029/2006GL026496, 2006.

Chevallier, F., Wang, T., Ciais, P., Maignan, F., Bocquet, M., Altaf, A.-M., Cescatti, A., Chen, J., Dolman, A. J., Law, B. E., Margolis, H. A., Montagnani, L., and Moors, E.: What eddycovariance measurements tell us about prior land flux errors in $\mathrm{CO}_{2}$ flux inversion schemes, Global Biogeochem. Cy., 26, GB1021, doi:10.1029/2010GB003974, 2012.

Chiesi, M., Fibbi, L., Genesio, L., Gioli, B., Magno, R., Maselli, F., Moriondo, M., and Vaccari, F.-P.: Integration of ground and satellite data to model Mediterranean forest processes, Int. J. App. Earth Obs., 13, 504-515, 2011.

Ciais, P., Peylin, P., and Bousquet, P.: Regional biospheric carbon fluxes as inferred from atmospheric $\mathrm{CO}_{2}$ measurements, Ecol. Appl., 10, 1574-1589, 2000.

Dee, D.-P., Uppala, S.-M., Simmons, A.-J., Berrisford, P., Poli, P., Kobayashi, S., Andrae, U., Balmaseda, M.-A., Balsamo, G., Bauer, P., Bechtold, P., Beljaars, A.-C.-M., van de Berg, L., Bidlot, J., Bormann, N., Delsol, C., Dragani, R., Fuentes, M., Geer, A.-J., Haimberger, L., Healy, S.-B., Hersbach, H., Hólm, E.-V., Isaksen, L., Kållberg, P., Köhler, M., Matricardi, M., Mcnally, A.-P., Monge-Sanz, B.-M., Morcrette, J.-J., Park, B.-K., Peubey, 
C., de Rosnay, P., Tavolato, C., Thépaut, J.-N., and Vitart, F.: The ERA-Interim reanalysis: configuration and performance of the data assimilation system, Q. J. R. Meteorol. Soc., 137, 553-597, 2011.

Delpierre, N., Soudani, K., François, C., Köstner, B., Pontailler, J.-Y., Nikinmaa, E., Misson, L., Aubinet, M., Bernhofer, C., Granier, A., Grünwald, T., Heinesch, B., Longdoz, B., Ourcival, J.- M., Rambal, S., Vesala, T., and Dufrêne, E.: Exceptional carbon uptake in European forests during the warm spring of 2007: a data-model analysis, Glob. Change Biol., 15, 1455-1474, 2009.

Dietiker, D., Buchmann, N., and Eugster, W.: Testing the ability of the DNDC model to predict $\mathrm{CO}_{2}$ and water vapour fluxes of a Swiss cropland site, Agriculture, Ecosyst. Environ., 139, 396401, 2010.

Dolman, A.-J., Noilhan, J., Durand, P., Sarrat, C., Brut, A., Piquet, B., Butet, A., Jarosz, N., Brunet, Y., Loustau, D., Lamaud, E., Tolk, L., Ronda, R., Miglietta, F., Gioli, B., Magliulo, V., Esposito, M., Gerbig, C., Korner, S., Glademard, R., Ramonet, M., Ciais, P., Neininger, B., Hutjes, R-W.-A., Elbers, J.-A., Macatangay, R., Schrems, O., Perez-Landa, G., Sanz, M.-J., Scholz, Y., Facon, G., Ceschia, E., and Beziat, P.: The CarboEurope Regional Experiment Strategy, Bull. Am. Meteorol. Soc., 87, 13671379, 2006.

Eidenshink, J. C. and Faundeen, J. L.: The 1 km AVHRR global land data set: first stages in implementation, Int. J. Remote Sens., 15, 3443-3462, 1994.

Etzold, S., Buchmann, N., and Eugster, W.: Contribution of advection to the carbon budget measured by eddy covariance at a steep mountain slope forest in Switzerland, Biogeosciences, 7, 24612475, doi:10.5194/bg-7-2461-2010, 2010.

Friedl, M. A., McIvera, D. K., Hodgesa, J. C. F., Zhanga, X. Y., Muchoneyb, D., Strahlera, A. H., Woodcocka, C. E., Gopala, S., Schneidera, A., Coopera, A., Baccinia, A., Gaoa, F., and Schaafa, C.: Global land cover mapping from MODIS: algorithms and early results, Remote Sens. Environ., 83, 287-302, 2002.

Gabriel, P., Gielen, B., Zona, D., Rodrigues, A., Rambal, S., Janssens, I., adn Ceulemans, R.: Carbon and water vapor fluxes over four forests in two contrasting climatic zones, Agr. Forest Meteorol., 180, 211-224, 2013.

Garbulsky, M.-F., Penuelas, J., Papale, D., and Filella, I.: Remote estimation of carbon dioxide uptake by a Mediterranean forest, Glob. Change Biol., 14, 2860-2867, 2008.

Garrigues, S., Olioso, A., Calvet, J. C., Martin, E., Lafont, S., Moulin, S., Chanzy, A., Marloie, O., Buis, S., Desfonds, V., Bertrand, N., and Renard, D.: Evaluation of land surface model simulations of evapotranspiration over a 12-year crop succession: impact of soil hydraulic and vegetation properties, Hydrol. Earth Syst. Sci., 19, 3109-3131, doi:10.5194/hess-19-31092015, 2015.

Gielen, B., B De Vos, Campioli, M., Neirynck, J., Papale, D., Verstraeten, A., Ceulemans, R., and Janssens, I.: Biometric and eddy covariance-based assessment of decadal carbon sequestration of a temperate Scots pine forest, Agr. Forest Meteorol., 174, 135$143,2013$.

Gioli, B, Miglietta, F, Vaccari, F.-P, Zaldei, A., and De Martino, B.: The Sky Arrow ERA, an innovative airborne platform to monitor mass, momentum and energy exchange of ecosystems, Ann. Geophys., 49, 109-116, 2006,

http://www.ann-geophys.net/49/109/2006/.
Göckede, M., Foken, T., Aubinet, M., Aurela, M., Banza, J., Bernhofer, C., Bonnefond, J. M., Brunet, Y., Carrara, A., Clement, R., Dellwik, E., Elbers, J., Eugster, W., Fuhrer, J., Granier, A., Grünwald, T., Heinesch, B., Janssens, I. A., Knohl, A., Koeble, R., Laurila, T., Longdoz, B., Manca, G., Marek, M., Markkanen, T., Mateus, J., Matteucci, G., Mauder, M., Migliavacca, M., Minerbi, S., Moncrieff, J., Montagnani, L., Moors, E., Ourcival, J.-M., Papale, D., Pereira, J., Pilegaard, K., Pita, G., Rambal, S., Rebmann, C., Rodrigues, A., Rotenberg, E., Sanz, M. J., Sedlak, P., Seufert, G., Siebicke, L., Soussana, J. F., Valentini, R., Vesala, T., Verbeeck, H., and Yakir, D.: Quality control of CarboEurope flux data - Part 1: Coupling footprint analyses with flux data quality assessment to evaluate sites in forest ecosystems, Biogeosciences, 5, 433-450, doi:10.5194/bg-5-433-2008, 2008.

Groenendijk, M., Dolman A.-J., van der Molen, M.-K., Leunung, R., Arneth, A., Delpierre, N., Gash, J.-H.-C., Lindroth, A., Richardson, A.-D., Verbeeck, H., and Wohlfahrt., G.: Assessing parameter variability in a photosynthesis model within and between plant functional types using global Fluxnet eddy covariance data, Agr. Forest Meteorol. 151, 22-38 , 2011.

Guidolotti, G., Rey, A., D’Andrea, E., Matteucci, G., and De Angelis, P.: Effect of environmental variables and stand structure on ecosystem respiration components in a Mediterranean beech forest, Tree Physiol., 33, 960-972, 2013.

Gurney, K.-R., Law, R.-M., Denning, A.-S., Rayner, P.-J., Baker, D., Bousquet, P., Bruhwiler, L., Chen, Y.-H., Ciais, P., Fan, S., Inez Y. F., Gloor, M., Heimann, M., Higuchi, K., John, J., Maki, T., Maksyutov, S., Masarie, K., Peylin, P., Prather, M., Bernard C. P., Randerson, J., Sarmiento, J., Taguchi, S., Takahashi, T., and Yuen, C. W.: Towards robust regional estimates of $\mathrm{CO}_{2}$ sources and sinks using atmospheric transport models, Nature, 415, 626630, 2002.

Helfter, C., Campbell, C., Dinsmore, K.-J., Drewer, J., Coyle, M., Anderson, M., Skiba, U., Nemitz, E., Billett, M.-F., and Sutton, M.-A.: Drivers of long-term variability in $\mathrm{CO}_{2}$ net ecosystem exchange in a temperate peatland, Biogeosciences, accepted, 2015.

Hilton, T. W., Davis, K. J., Keller, K., and Urban, N. M.: Improving North American terrestrial $\mathrm{CO}_{2}$ flux diagnosis using spatial structure in land surface model residuals, Biogeosciences, 10, 4607-4625, doi:10.5194/bg-10-4607-2013, 2013.

Houweling, S., Breon, F.-M., Aben, I., Rödenbeck, C., Gloor, M., Heimann, M., and Ciais, P.: Inverse modeling of $\mathrm{CO}_{2}$ sources and sinks using satellite data: a synthetic inter-comparison of measurement techniques and their performance as a function of space and time, Atmos. Chem. Phys., 4, 523-538, doi:10.5194/acp-4523-2004, 2004.

Hsieh, C. I., Katul, G. G., and Chi, T. W.: An approximate analytical model for footprint estimation of scalar fluxes in thermally stratified atmospheric flows, Adv. Water Resour., 23, 765-772, 2000 .

Jans, W.-W.-P., Jacobs, C.-M.-J., Kruijt, B., Elbers, J.-A., Barendse, S., and Moors, E.-J.: Carbon exchange of a maize (Zea mays L.) crop: influence of phenology, Agriculture, Ecosyst. Environ., 139, 316-324, 2010.

Elbers, J.-A., Jacobs, C.-M.-J., Kruijt, B., Jans, W.-W.-P., and Moors, E.-J.: Assessing the uncertainty of estimated annual totals of net ecosystem productivity: A practical approach applied 
to a mid latitude temperate pine forest, Agr. Forest Meteorol., 151, 1823-1830, 2011.

Jarosz, N., Brunet, Y., Lamaud, E., Irvine, M., Bonnefond, J.-M., and Loustau, D.: Carbon dioxide and energy flux partitioning between the understorey and the overstorey of a maritime pine forest during a year with reduced soil availability, Agr. Forest Meteorol., 148, 1508-1523, 2008.

Jongen, M., Pereira, J., Saires., L.-M.-I., and Pio, C.-A.: The effects of drought and timing of precipitation on the inter-annual variation in ecosystem-atmosphere exchange in a Mediterranean grassland, Agr. Forest Meteorol., 151, 595-606, 2011.

Jung, M., Henkel, K., Herold, M., and Churkina, G.: Exploiting synergies of global land cover products for carbon cycle modeling, Remote Sens. Environ., 101, 534-553, 2006.

Jung, M., Reichstein, M., and Bondeau, A.: Towards global empirical upscaling of FLUXNET eddy covariance observations: validation of a model tree ensemble approach using a biosphere model, Biogeosciences, 6, 2001-2013, doi:10.5194/bg-6-20012009, 2009.

Keenan, T., Garcia, R., Friend, A.-D., Zaehle, S., Gracia, C., and Sabate, S.: Improved understanding of drought controls on seasonal variation in Mediterranean forest canopy $\mathrm{CO}_{2}$ and water fluxes through combined in situ measurements and ecosystem modeling, Biogeosciences, 6, 2285-2329, 2009,

http://www.biogeosciences.net/6/2285/2009/.

Klumpp, K., Tallec, T., Guix, N., and Soussana, J.-F.: Long-term impacts of agricultural practices and climatic variability on carbon storage in a permanent pasture, Glob. Change Biol., 17, 3534-3545, 2011.

Knohl, A., Schulze, E.-D., Kolle, O., and Buchmann, N.: Large carbon uptake by an unmanaged 250-year-old deciduous forest in Central Germany, Agr. Forest Meteorol. 118, 151-167, 2003.

Kottek, M., Grieser, J., Beck, C., Rudolf, B., and Rubel, F.: World Map of the Köppen-Geiger climate classification updated, Meteorologische Zeitschrift, 15, 259-263, 2006.

Krinner, G., Viovz, N., Ogee, J., Polcher, J., Friedlingstein, P., Ciais, P., Sitch, S., and Prentice, C.-I.: A dynamic global vegetation model for studies of the coupled atmospherebiosphere system, Global Biogeochem. Cy., 19, GB1015, doi:10.1029/2003GB002199, 2005.

Kutscha, W. L., Aubinet, M., Buchmann, N., Smith, P., Osborne, B., Eugsterc, W., Wattenbach, M., Schrumpf, M., Schulze, E. D., Tomelleri, E., Ceschia, E., Bernhofer, C., éziat, P., Carrara, A., Di Tommasi, P., Grünwald, T., Jones, M., Magliulo, V., Marloie, O., Moureaux, C., Olioso, A., Sanz, M. J., Saunders, M., Søgaard, H., and Ziegler, W.: The net biome production of full crop rotations in Europe, Agr. Ecosyst. Environ., 139, 336-345, 2010.

Lasslop, G., Reichstein, M., Kattge, J., and Papale, D.: Influences of observation errors in eddy flux data on inverse model parameter estimation, Biogeosciences, 5, 1311-1324, doi:10.5194/bg5-1311-2008, 2008.

Lauvaux, T., Uliasz, M., Sarrat, C., Chevallier, F., Bousquet, P., Lac, C., Davis, K. J., Ciais, P., Denning, A. S., and Rayner, P. J.: Mesoscale inversion: first results from the CERES campaign with synthetic data, Atmos. Chem. Phys., 8, 3459-3471, doi:10.5194/acp-8-3459-2008, 2008.

Lauvaux, T., Gioli, B., Sarrat, C., Rayner, P.-J., Ciais, P., Chevallier, F., Noilhan, J., Miglietta, F., Brunet, Y., Ceschia, E., Dolman, H., Elbers, J.-A., Gerbig, C., Hutjes, R., Jarosz, N., Legain, D., and Uliasz, M.: Bridging the gap between atmospheric concentrations and local ecosystem measurements, Geophys. Res. Lett., 36, L19809, doi:10.1029/2009GL039574, 2009.

Lauvaux, T., Schuh, A.-E., Bocquet, M., Wu, L., Richardson, S., Miles, N., and Davis, K.-J.: Network design for mesoscale inversions of $\mathrm{CO}_{2}$ sources and sinks, Tellus B, 64, 17980 , doi:10.3402/tellusb.v64i0.17980, 2012.

Longdoz, B., Gross, P., and Granier, A.: Multiple quality tests for analysing $\mathrm{CO}_{2}$ fluxes in a beech temperate forest, Biogeosciences, 5, 719-729, doi:10.5194/bg-5-719-2008, 2008.

Mahadevan, P., Wofsy, S.-C., Matross, D.-M., Xiao, X., Dunn, A.L., Lin, J.-C., Gerbig, C., Munger, J.-W., Chow, V.-Y., and Gottlieb, E.-W.: A satellite-based biosphere parameterization for net ecosystem $\mathrm{CO}_{2}$ exchange: Vegetation Photosynthesis and Respiration Model (VPRM), Global Biogeochem. Cy., 22, GB2005, doi:10.1029/2006GB002735, 2008.

Marcolla, B., Pitacco, A., and Cescatti, A.: Canopy architecture and turbulence structure in a coniferous forest, Bound.-Lay. Meteorol., 108, 39-59, 2003.

Marcolla, B., Cescatti, A., Montagnani, L., Manca, G., Kerschbaumer, G., and Minerbi, S.: Importance of advection in the atmospheric $\mathrm{CO}_{2}$ exchanges of an alpine forest, Agr. Forest Meteorol., 130, 193-206, 2005.

Marcolla, B., Cescatti, A., Manca, G., Zorer, R., Cavagna, M., Fiora, A., Gianelle, D., Rodeghiero, M., Sottocornola, M., and Zampedri, R.: Climatic controls and ecosystem responses drive the inter-annual variability of the net ecosystem exchange of an alpine meadow, Agr. Forest Meteorol., 151, 1233-1243, 2011.

Matteucci, M., Gruening, C., Goded., B., I., and Cescatti, A.: Soil and ecosystem carbon fluxes in a Mediterranean forest during and after drought, AGROCHIMICA, vol. LVIII, 91-115, 2014.

Meesters, A.-G.-C.-A., Tolk, L.-F., Peters, W., Hutjes, R.-W.-A., Vellinga, O.-S., Elbers, J.-A., Vermeulen, A.-T., van der Laan, S., Neubert, R.-E.-M., Meijer, H.-A.-J., and Dolman, A. J.: Inverse carbon dioxide flux estimates for the Netherlands, J. Geophys. Res.-Atmos., 117, 1984-2012, 2012.

Meijide, A., Manca, G., Goded, I., Magliulo, V., di Tommasi, P., Seufert, G., and Cescatti, A.: Seasonal trends and environmental controls of methane emissions in a rice paddy field in Northern Italy, Biogeosciences, 8, 3809-3821, doi:10.5194/bg8-3809-2011, 2011.

Michalak, A.-M., Bruhwiler, L., and Tans, P.-P.: A geostatistical approach to surface flux estimation of atmospheric trace gases, J. Geophys. Res., 109, D14109, doi:10.1029/2003JD004422, 2004.

Montagnani, L., Manca, G., Canepa, E., Georgieva, E., Acosta, M., Feigenwinter, C., Janous, D., Kerschbaumer, G., Lindroth, A., Minach, L., Minerbi, S., Möder, M., Pavelka, M., Seufert, G., Yeri, M., and Yiegler, W.: A new mass conservation approach to the study of $\mathrm{CO}_{2}$ advection in an alpine forest, J. Geophys. Res.-Atmos., 114, D07306, doi:10.1029/2008JD010650, 2009.

Moors, E.-J., Jacobs, C., Jans, W., Supit, I., Kutsch, W.-1, Bernhofer, C., Bezat, P., Buchmann, N., Carrara, A., Ceschia, E., Elbers, J., Eugster, W., Kruijt, B., Loubet, B., Magliulo, E., Moureaux, C., Olioso, A., Saunders, M., and Soegaard, H.: Variability in carbon exchange of European croplands, Agr. Ecosyst. Environ., 139, 325-335, 2010.

Moureaux, C., Debacq, A., Bodson, B., Heinesch, B., and Aubinet, M.: Annual net ecosystem carbon exchange by a sugar beet crop, Agr. Forest Meteorol., 139, 25-39, 2006. 
Nagy, Z., Pintér, K., Czóbel, Sz., Balogh, J., Horváth, L., Fóti, Sz., Barcza, Z., Weidinger, T., Csintalan, Zs., Dinh, N., Q., Grosz, B., and Tuba, Z.: The carbon budget of a semiarid grassland in a wet and a dry year in Hungary, Agr. Ecosyst. Environ., 121, 21-29, 2007.

Olson, J.-S.: Global ecosystem framework-definitions, USGS EROS Data Cent, Intern, Rep. Sioux Falls SD, 37, 1994.

Papale, D. and Valentini, R., A new assessment of European forests carbon exchanges by eddy fluxes and artificial neural network spatialization, Glob. Change Biol., 9, 525-535, 2003

Peters, W., Jacobson, A.-R., Sweeney, C., Andrews, A.-E., Conway, T.-J., Masarie, K.-B., Miller, J., Bruhwiler, L.-M.-P., Petron, G., Hirsch, A.-I., Worthy, D.-E.-J., van der Werf, G.-R., Wennberg, J.-T.-R.-P.-O., Krol, M.-C., and Tans, P.-P.: An atmospheric perspective on North American carbon dioxide exchange: CarbonTracker, Proc. Natl. Acad. Sci., 104, 18925-18930, 2007.

Peylin, P., Rayner, P. J., Bousquet, P., Carouge, C., Hourdin, F., Heinrich, P., Ciais, P., and AEROCARB contributors: Daily $\mathrm{CO}_{2}$ flux estimates over Europe from continuous atmospheric measurements: 1, inverse methodology, Atmos. Chem. Phys., 5, 3173-3186, doi:10.5194/acp-5-3173-2005, 2005.

Piao, S., Fang, J., Ciais, P., Peylin, P., Huang, Y., Sitch, S., and Wang, T.: The carbon balance of terrestrial ecosystems in China, Nature, 458, 1009-1013, 2009.

Pillai, D., Gerbig, C., Kretschmer, R., Beck, V., Karstens, U., Neininger, B., and Heimann, M.: Comparing Lagrangian and Eulerian models for $\mathrm{CO}_{2}$ transport- a step towards Bayesian inverse modeling using WRF/STILT-VPRM, Atmos. Chem. Phys., 12, 8979-8991, doi:10.5194/acp-12-8979-2012, 2012.

Prescher, A., K., Grünwald, T., and Bernhofer, C.: Land use regulates carbon budgets in eastern Germany: From NEE to NBP, Agr. Forest Meteorol., 150, 1016-1025, 2010.

Rey, A., Belelli-Marchesini, L., Were, A., Serrano-Ortiz, P., Etiope, G., Papale, D., Domingo, F., and Pegoraro, E.: Wind as a main driver of the net ecosystem carbon balance of a semiarid Mediterranean steppe in the South East of Spain, Glob. Change Biol., 18, 539-554, 2012.

Richardson, A.-D., Hollinger, D.-Y., Burba, G.-G., Davis, K.-J., Flanagan, L.-B., Katul, G.-G., William M.-J., Ricciuto, D.-M., Stoy, P.-C., Suyker, A.-E., and Verma, S., Wofsy, S. C.: A multisite analysis of random error in tower-based measurements of carbon and energy fluxes, Agr. Forest Meteorol., 136, 1-18, 2006.

Richardson, A.-D., Mahecha, M.-D., Falge, E., Kattge, J., Moffat, A.-M., Papale, D., Reichstein, M., Stauch, V.-J., Braswell, B.H., Churkina, G., and Kruijt, B., and Hollinger, D. Z.: Statistical properties of random $\mathrm{CO}_{2}$ flux measurement uncertainty inferred from model residuals, Agr. Forest Meteorol., 148, 38-50, 2008.

Rödenbeck, C.: Estimating $\mathrm{CO}_{2}$ sources and sinks from atmospheric mixing ratio measurements using a global inversion of atmospheric transport, Jena, Max Planck Institute for Biogeochemistry, technical report 6, 2005.

Rödenbeck, C., Gerbig, C., Trusilova, K., and Heimann, M.: A twostep scheme for high-resolution regional atmospheric trace gas inversions based on independent models, Atmos. Chem. Phys., 9, 5331-5342, doi:10.5194/acp-9-5331-2009, 2009.

Rödenbeck, C., Houweling, S., Gloor, M., and Heimann, M.: Timedependent atmospheric $\mathrm{CO}_{2}$ inversions based on interannually varying tracer transport, Tellus B, 55, 488-497, 2003a.
Rödenbeck, C., Houweling, S., Gloor, M., and Heimann, M.: $\mathrm{CO}_{2}$ flux history 1982-2001 inferred from atmospheric data using a global inversion of atmospheric transport, Atmos. Chem. Phys., 3, 1919-1964, doi:10.5194/acp-3-1919-2003, 2003 b.

Rodgers, C. D.: Inverse methods for Atmosphere Sounding: Theory and Practice, World Sci., River Edge, N. J., 2000.

Schuh, A.-E., Denning, A.-S., Corbin, K.-D., Baker, I.-T., Uliasz, M., Parazoo, N., Andrews, A.-E., and Worthy, D.-E.-J.: A regional high-resolution carbon flux inversion of North America for 2004, Biogeosciences, 7, 1625-1644, doi:10.5194/bg-71625-2010, 2010.

Skiba, U., Jones, S.-K., Drewer, J., Helfter, C., Anderson, M., Dinsmore, K., McKenzie, R., Nemitz, E., and Sutton, M.-A.: Comparison of soil greenhouse gas fluxes from extensive and intensive grazing in a temperate maritime climate, Biogeosciences, 10, 1231-1241, doi:10.5194/bg-10-1231-2013, 2013.

Soussana, J.-F., Allard, V., Pilegaard, K., Ambus, P., Amman, C., Campbell, C., Ceschia, E., Clifton-Brown, J., Czöbel, Sz., Domingues, R., Flechard, C., Fuhrer, J., Hensen, A., Horvath, L., Jones, M., Kasper, G., Martin, C., Nagy, Z., Neftel, A., Raschi, A., Baronti, S., Rees, R. M., Skiba, U., Stefani, P., Manca, G., Sutton, M., Tuba, Z., and Valentini, R.: Full accounting of the greenhouse gas $\left(\mathrm{CO}_{2}, \mathrm{~N}_{2} \mathrm{O}, \mathrm{CH}_{4}\right)$ budget of nine European grassland sites, Agriculture, Ecosyst. Environ., 121, 121-134, 2007.

Suni, T., Rinne, J., Reissel, A., Altimir, N., Keronen, P., Rannik, Ü., Dal Maso, M., Kulmala, M., and Vesala, T.: Long-term measurements of surface fluxes above a Scots pine forest in Hyytil, southern Finland, 1996-2001, Boreal Environ. Res., 4, 287-301, 2003.

Tallec, T., Béziat, P., Jarosz, N., Rivalland V., and Ceschia E.: Crops water use efficiencies: comparison of stand, ecosystem and agronomical approaches, Agr. Forest Meteorol., 168, 69-81, 2013.

Taufarova, K., Havrankova, K., Dvorská, A., Pavelka, M., Urbaniak, M., and Janous, D.: Forest ecosystem as a source of $\mathrm{CO}_{2}$ during growing season: relation to weather conditions, Int. Agrophys., 28, 239-249, 2014.

Tolk, L.-F., Dolman, A.-J., Meesters, A.-G.-C.-A., and Peters, W.: A comparison of different inverse carbon flux estimation approaches for application on a regional domain, Atmos. Chem. Phys., 11, 10349-10365, doi:10.5194/acp-11-10349-2011, 2011.

Venzon, D. J. and Moolgavkar, S. H.: A method for computing profile-likelihood-based confidence intervals, J. Roy. Stat. Soc., 37, 87-94, 1988.

Weedon, G.-P., Balsamo, G., Bellouin, N., Gomes, S., Best, M.J., and Viterbo, P.: The WFDEI meteorological forcing data set: WATCH Forcing Data methodology applied to ERA-Interim reanalysis data, Water Resour. Res., 50, 7505-7514, 2014.

Wei, S, Yi, C., Hendrey, G., Eaton, T., Rustic, G., Wang, S., Liu, H., Krakauer, N.-Y., Wang, W., Desai, A.-R., Montagnani, L., Kyaw Tha Paw U., Falk. M., Black, A., Bernhofer. C., Grünwald, T., Laurila, T., Cescatti, A., Moors, E., Bracho, R., and Valentini, R.: Data-based perfect-deficit approach to understanding climate extremes and forest carbon assimilation capacity, Environ. Res. Lett., 9, 065002, 2014.

Wu, L., Bocquet, M., Lauvaux, T., Chevallier, F., Rayner, P., and Davis, K.: Optimal representation of source-sink fluxes for mesoscale carbon dioxide inversion with synthetic 
data, J. Geophys. Res.-Atmos. (1984-2012), 116, D21304, doi:10.1029/2011JD016198, 2011.

Xiao, J. F., Zhuang, Q. L., Baldocchi, D. D., Law, B. E., Richardson, A. D., Chen, J., Oren, R., Starr, G., Noormets, A., Ma, S., Verma, S. B., Wharton, S., Wofsy, S. C., Bolstad, P. V., Burns, S. P., Cook, D. R., Curtis, P. S., Drake, B. G., Falk, M., Fischer, M. L., Foster, D. R., Gu, L., Hadley, J. L., Hollinger, D. Y., Katul, G. G., Litvak, M., Martin, T. A., Matamala, R., McNulty, S., Meyers, T. P., Monson, R. K., Munger, J. W., and Oechel, W. C.: Estimation of net ecosystem carbon exchange for the conterminous United States by combining MODIS and AmeriFlux data, Agr. Forest Meteorol., 148, 1827-1847, 2008.
Zeeman, M., J., Hiller, R., Gilgen, A.-K., Michna, P., Plüss, P., Buchmann, N., and Eugster, W.: Management and climate impacts on net $\mathrm{CO}_{2}$ fluxes and carbon budgets of three grasslands along an elevational gradient in Switzerland, Agric. For. Meteorol., 150, 519-530, 2010.

Zweifel, R., Eugster, W., Etzold, S., Dobbertin, M., Buchmann, N., and Häsler, R.: Link between continuous stem radius changes and net ecosystem productivity of a subalpine Norway spruce forest in the Swiss Alps, New Phytol., 187, 819-830, 2010. 